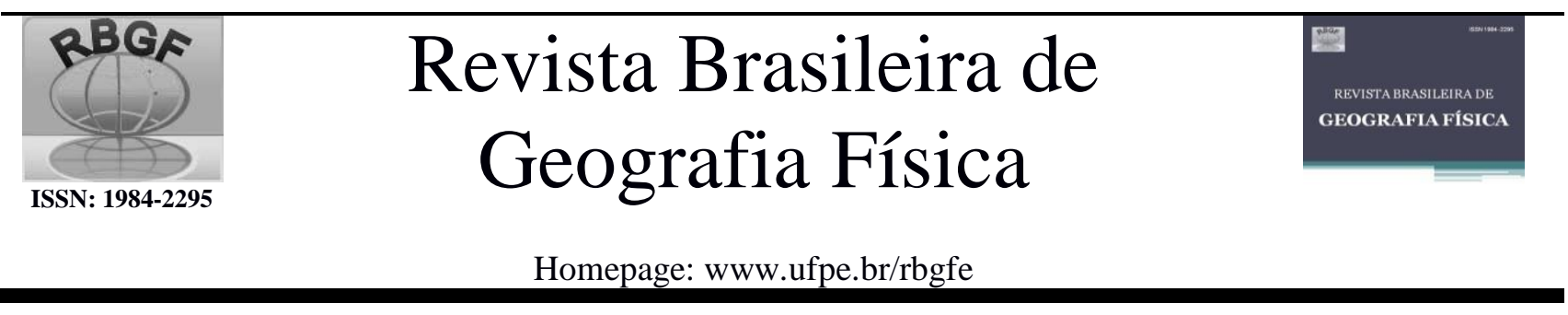

\title{
Comunidade Halofítica Herbáceo-arbustiva em Perímetro Irrigado do Município de Pentecoste-CE ${ }^{1}$
}

\begin{abstract}
Oriel Herrera Bonilla ${ }^{2}$, Francisco Yago Elias de Castro Dias ${ }^{3}$, Eliseu Marlônio Pereira de Lucena² ${ }^{\text {, Claudivan }}$ Feitosa de Lacerda ${ }^{4}$, Maria Iracema Bezerra Loiola ${ }^{5}$

${ }^{1}$ Parte da pesquisa de Pós-Doutorado, executada pelo primeiro e supervisionada pelo quarto autor, no âmbito do Programa de Pós-Graduação em Engenharia Agrícola da Universidade Federal do Ceará, Fortaleza-CE, Brasil.

${ }^{2}$ Doutor, Professor Associado do Curso de Ciências Biológicas e do Programa de Pós-Graduação em Ciências Naturais, Universidade Estadual do Ceará, Campus do Itaperi, CEP 60.714-903, Fortaleza, CE. E-mail: oriel.herrera@ uece.br - autor correspondente; eliseu.lucena@uece.br.

${ }^{3}$ Mestre, Mestrado Acadêmico em Recursos Naturais, Universidade Estadual do Ceará, Campus do Itaperi, CEP 60.714-903, Fortaleza, CE. E-mail: pa9910@gmail.com ${ }^{4}$ Doutor, Professor do Curso de Agronomia, Universidade Federal do Ceará, Campus do Pici, CEP 60455-760, Fortaleza, CE, Brasil. E-mail: claudivan@ @ hotmail.com ${ }^{5}$ Doutora, Professora do Curso de Ciências Biológicas, Universidade Federal do Ceará, Campus do Pici, CEP 60455-760, Fortaleza, CE, Brasil. E-mail: iloiola@ufc.br
\end{abstract}

Artigo recebido em 01/06/2019 e aceito em 30/06/2019

\section{R E S U M O}

A salinização dos solos e um problema que ocorre quando existe um excesso de sais na solução do solo, afetando a pecuária e a agricultura, causando prejuízos econômicos e ambientais. O trabalho objetivou avaliar comunidades vegetais presentes em áreas salinizadas do perímetro irrigado Curu-Recuperação, em Pentecoste-CE. Foram realizadas cinco coletas em duas áreas do perímetro, em três épocas do ano (início da quadra chuvosa, final da quadra chuvosa e estação seca) constituídas de contagem de plantas e coletas de solo. Registrou-se a presença de 37 espécies divididas em 14 famílias, sendo Fabaceae a mais representativa. As espécies Blutaparon vermiculare L., Cyperus rotundus L. e Malachra fasciata Jacq., foram as mais representativas, sendo a primeira espécie com a maior uniformidade na distribuição dentre todas as coletas. $\mathrm{O}$ índice de Shannon obtido foi semelhante ao encontrado em áreas sob o efeito do estresse salino. Deste modo, foi possível identificar espécies tolerantes a salinidade no solo e com aplicações alimentícias, medicinais, para uso em programas de haloforraginocultura e na recuperação de solos degradados. Palavras-chave: Halófita, salinidade, semiárido.

\section{Herbaceous-shrub Halophytic Community of the Irrigated Perimeter of the County Pentecoste-CE}

\section{A B S T R A C T}

Salinization of soils is a problem that occurs when there is an excess of salts in the soil solution, affecting livestock and agriculture, causing economic and environmental damages. The objective of this work was to evaluate plant communities present in salinized areas of the irrigated perimeter Curu-Recuperação, in Pentecoste-CE. Five collections were carried out in two perimeter areas, in three seasons of the year (beginning of the rainy season, end of the rainy season and dry season), consisting of plant counts and soil collections. The presence of 37 species divided into 14 families was recorded, with Fabaceae being the most representative. The species Blutaparon vermiculare L., Cyperus rotundus L. and Malachra fasciata Jacq., were the most representative, being the first species with the greatest uniformity in the distribution in all collections. The Shannon index obtained was similar to that found in areas under the effect of saline stress. Therefore, it was possible to identify species tolerant to salinity in the soil and with food and medicinal applications, for use in haloforraginculture programs and in the recovery of degraded soils.

Keywords: Halophytes, salinity, semiarid.

\section{Introdução}

Os solos acometidos por sais, conhecidos como halomórficos ou solos salinos e sódicos, são solos caracterizados pela presença de sais solúveis, sódio trocável ou ambos, em camadas próximas à superfície. Quando a concentração de sais é elevada, a sua condutividade elétrica também aumenta, sendo considerado assim um 
solo salinizado quando a condutividade elétrica do extrato de saturação (CEes) é $\geq 4 \mathrm{dS} \mathrm{m}^{-1}$ (USSL Staff, 1954; Ribeiro, 2010; Major e Sales, 2010).

Segundo Zerai et al. (2010) a ocorrência da problemática da salinização se dá principalmente nas zonas áridas e semiáridas do globo, uma vez que nessas regiões existe um acentuado déficit hídrico, impedindo uma lixiviação satisfatória, bem como, uma alta taxa de evaporação, motivos esses que também explicam a pouca ocorrência desse problema nas regiões úmidas. No Nordeste brasileiro, cerca de $50 \%$ do território encontra-se em um clima semiárido, onde a excessiva evaporação produz o acúmulo de sais solúveis e o incremento do sódio trocável na superfície do solo, isto influencia negativamente a pecuária e a produção agrícola, trazendo como consequência o abandono das terras inviabilizando qualquer atividade (Medeiros et al., 2012; Medeiros et al., 2016; DNOCS, 2017).

O perímetro irrigado no município de Pentecoste-CE foi instalado pelo DNOCS em 1979, abrangendo uma superfície irrigada de aproximadamente 890 há, dividida em oito setores hidráulicos denominados núcleos, os quais vão da letra A à H (DNOCS, 2017). A degradação dos solos neste perímetro irrigado é decorrente do tipo de solo, da qualidade da água de irrigação, da falta de drenagem do excesso de água de irrigação e do tipo de irrigação praticada. Originalmente, esses solos têm uma concentração elevada de sais, dada sua formação (Neossolos Flúvicos), fatores que são potencializados quando o problema se agrava pela falta de manutenção do coletor principal, inexistência dos coletores secundários e de canais de drenagem no nível parcelar. A irrigação é por superfície, com intervalo de rega de oito dias, sem nenhum controle de medição do volume de água para as culturas (Albuquerque et al., 2018).

Passados 40 anos após a implantação do perímetro irrigado no município de PentecosteCE, identificam-se hoje, áreas sem implantação de culturas e lotes sem a presença do irrigante, demonstrando, claramente, o abandono dessas áreas.

Diante dessa problemática, a reestruturação e reabilitação dos solos salinizados é indispensável, tanto pela questão do equilíbrio ecológico dos locais, como para a economia dos países que apresentam a problemática, visando a reorganização do sistema de cultivo (Tavares Filho et al., 2012).
Nesse viés, as halófitas, plantas capazes de concentrar e metabolizar o excesso de sal presente no meio (Flowers et al., 2010; Rozema e Schat, 2013) são um importante recurso presente em áreas salinizadas. Além da produção de alimentos e bioprodutos para o homem, essas plantas podem ser utilizadas na recuperação de solos degradados, por meio da fitoextração (Mishra e Sangwan, 2016), bem como, na criação/restauração de marismas e recuperação de áreas costeiras degradadas (Costa, 2011).

Esforços realizados com a intenção de identificar tais plantas tolerantes à salinidade constituem um importante marco no âmbito da agricultura sustentável (Pandolfi et al., 2012), entretanto, tratando-se da Caatinga nordestina os estudos florísticos são escassos quando se trata do estrato herbáceo halofítico (Araújo et al., 2005; Costa et al., 2009; Meira de Andrade, 2009; Silva et al., 2009).

Nesse contexto, a pesquisa teve como objetivo caracterizar a florística e a estrutura do estrato herbáceo-arbustivo de duas áreas com solo salinizado do perímetro irrigado CuruRecuperação, no município de Pentecoste-CE, correlacionando-as com a condutividade elétrica, o pH e a umidade do solo.

\section{Material e Métodos}

\section{Descrição da Área Experimental}

A pesquisa foi executada entre os meses de abril/2016 a março/2017, com coletas no período chuvoso (meses de março e maio) e no período de seco (mês de outubro), em duas áreas do núcleo $\mathrm{D}$ do Perímetro Irrigado CuruRecuperação, no município de Pentecoste-CE (Figura 1) $\left(03^{\circ} 48^{\prime} 04.3^{\prime \prime} \mathrm{S} 39^{\circ} 18^{\prime} 11.3^{\prime \prime} \mathrm{W}\right.$ - área 1;

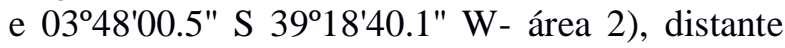
aproximadamente, $90 \mathrm{~km}$ da capital Fortaleza (Figuras 2A e 2B, respectivamente). O clima de acordo com a classificação Köeppen corresponde ao tipo BSw'h', semiárido quente e com baixa precipitação, com chuvas irregulares concentradas nos meses de janeiro a abril (EMBRAPA, 2001). A precipitação pluvial média anual é de $817,7 \mathrm{~mm}$ e a evaporação média anual de $1.474 \mathrm{~mm}$, o que gera um acentuado déficit hídrico. A temperatura média anual é em torno de $27^{\circ} \mathrm{C}$ e umidade relativa média do ar de 73,7\% (IPECE, 2016). 


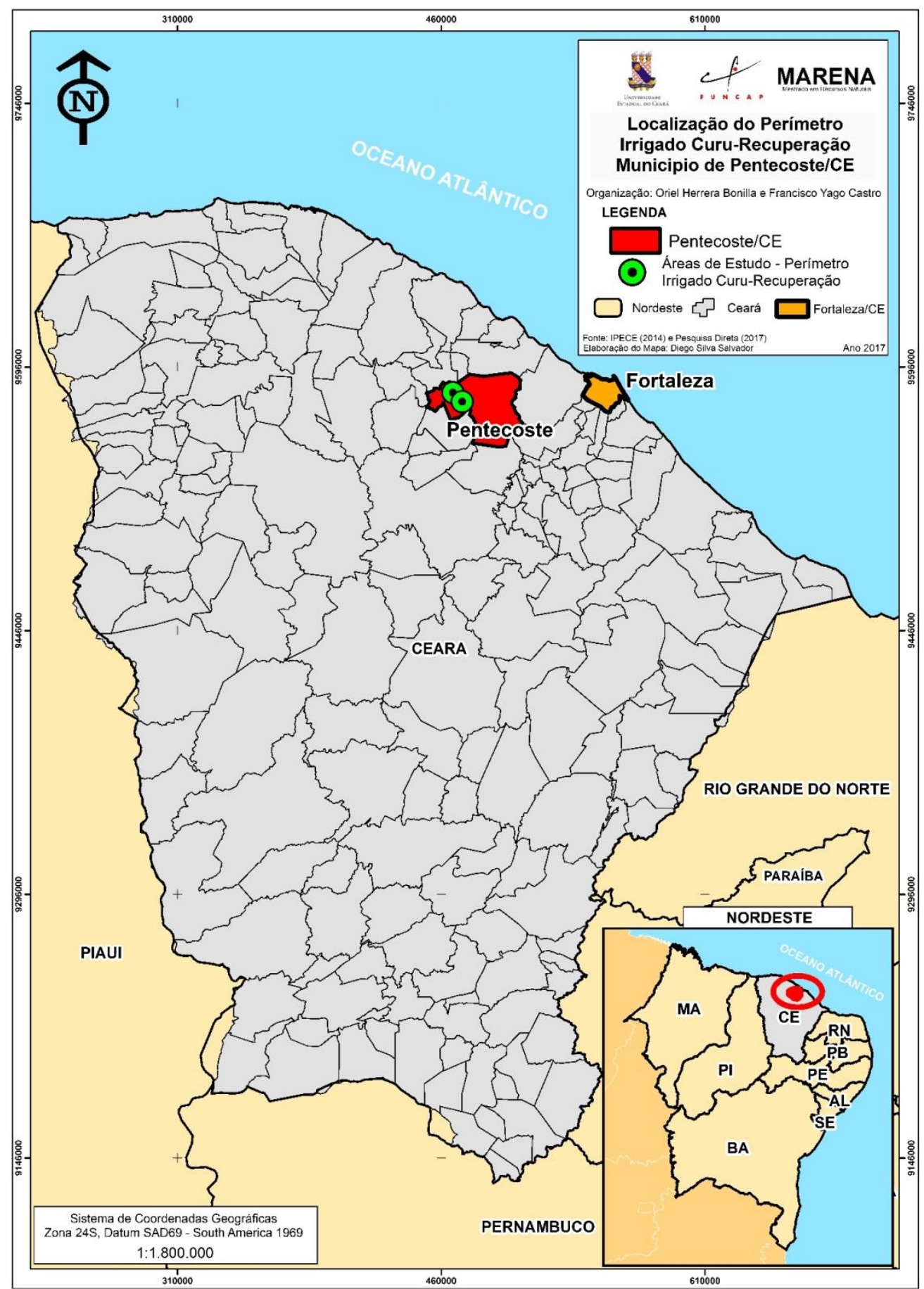

Figura 1. Localização do perímetro irrigado Curu-Recuperação no município de Pentecoste-CE.
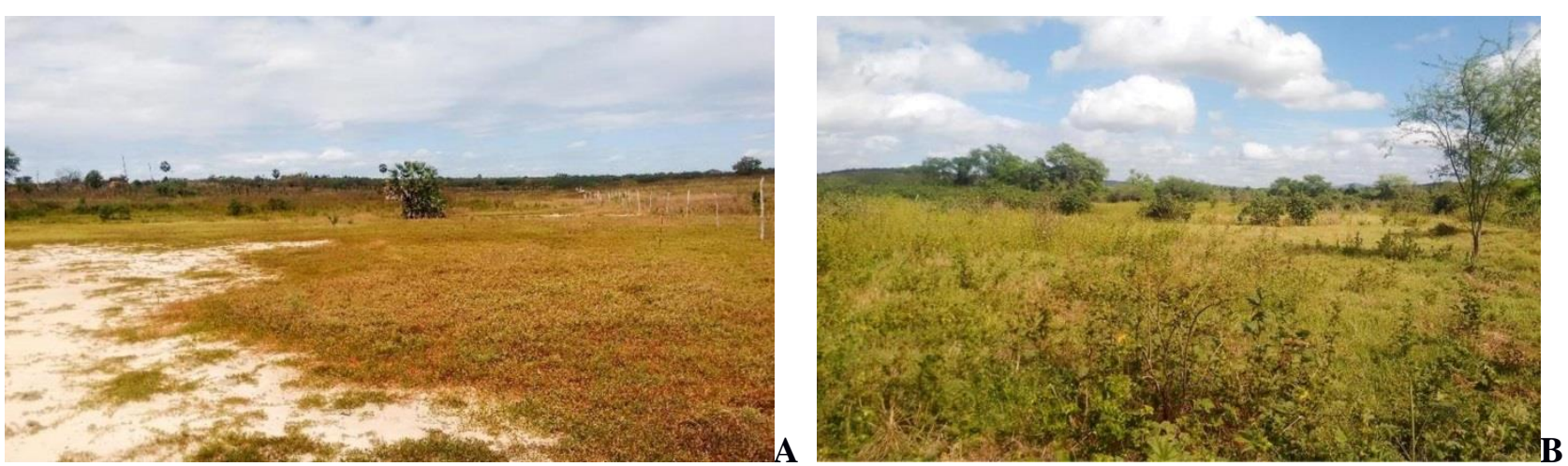

Figura 2. Áreas experimentais no núcleo D do perímetro irrigado Curu-Recuperação, Pentecoste-CE: A-Área 1 ; B-Área 2.

Herrera, B. O.; Dias, Y. E. C.; Lucena, E. M. P. de; Lacerda, C. L. de; Loiola, M. I. B. 
De acordo com o DNOCS (2017), o perímetro irrigado se localiza na região das baixas aluvionais, apresentando Neossolos Fluvicos de textura que varia entre média e pesada. $O$ suprimento hídrico é realizado por meio do Açude Público General Sampaio, que possui capacidade de armazenamento de $322.200 .000 \mathrm{~m}^{3}$ e pelo Açude Público Pereira de Miranda, com capacidade de $395.638 .000 \mathrm{~m}^{3}$. O sistema de irrigação do perímetro é feito completamente por superfície em sulcos, enquanto que a drenagem é feita por meio de drenos a céu aberto, sendo os principais coletores os rios Curu e Canindé.

A vegetação natural encontrada na região é composta por Caatinga Arbustiva Densa, Complexo vegetacional da Zona Litorânea e Floresta Mista Dicotillo-Palmacea, entretanto, no perímetro irrigado a mesma encontra-se bastante antropizada (IPECE, 2016).

\section{Coleta de Dados}

Inicialmente as áreas foram divididas em parcelas permanentes de $5 \times 5 \mathrm{~m}$, com o auxílio de uma trena, de forma aleatória, sendo 49 parcelas na área 1 e 25 parcelas na área 2, divididas em 6 e 5 blocos, respectivamente, obedecendo a gradientes visuais que mostraram presença de plantas halofíticas.

As amostragens em campo foram realizadas em três épocas: a primeira em maio de 2016, compreendendo o período referente ao final da quadra chuvosa; a segunda no mês de outubro/2016, compreendendo o mês com menor pluviosidade na região; e a terceira no mês de março/2017, pico da quadra chuvosa (Bezerra, 2006).

Foram realizadas cinco coletas, sendo três na área 1 (final da quadra chuvosa, estação seca e pico da quadra chuvosa) e duas na área 2 (final da quadra chuvosa e pico da quadra chuvosa). A coleta na estação seca da área 2 foi impossibilitada por um incêndio de origem desconhecido. Cada coleta foi considerada como uma amostra independente.

\section{Composição Florística e Estrutura Fitossociológica}

Para o estudo da composição florística do estrato herbáceo-arbustivo foi feita a coleta e herborização de todas as espécies encontradas nas parcelas de acordo com as técnicas de coleta, preservação e herborização de material botânico (Fidalgo e Bononi, 1989). As exsicatas foram identificadas e depositadas no Herbário Prisco
Bezerra (EAC), da Universidade Federal do Ceará (UFC). Para o levantamento florístico, foi lançado um quadrado de canos de PVC de 1 x $1 \mathrm{~m}$ (Figura 3) de forma aleatória dentro de cada uma das parcelas permanentes. Foram contabilizados todos os indivíduos herbáceos e arbustivos por espécie e estimados os seguintes atributos estruturais: frequência absoluta $(\mathrm{Fa})$, frequência relativa $(\mathrm{Fr}$; $\%)$, densidade absoluta ( $\mathrm{Da}$; ind. $\mathrm{m}^{-2}$ ), densidade relativa (Dr; \%), índice de similaridade de Sorensen (S) e índice de Shannon (H') (Oliveira e Amaral, 2004). Os parâmetros foram calculados com o auxílio do programa Fitopac 2.1 (Shepherd, 2010). Foi realizada uma análise de cluster por agrupamento pareado não ponderado baseado na média aritmética (UPGMA), utilizando o programa MVSP 3.2.

\section{Análise de Solo}

Em cada um dos vértices do quadrado de PVC utilizado na amostragem do levantamento florístico, foram coletadas amostras de solo na profundidade de $0-20 \mathrm{~cm}$, sendo misturadas em um balde e formando uma amostra composta de solo por parcela. Uma porção da amostra composta foi armazenada em potes de metal hermeticamente fechados, de forma que as amostras não perdessem nem ganhassem umidade, e o resto da amostra foi armazenado e identificado em sacos plásticos.

As amostras de solo dos potes de metal foram pesadas em balança analítica, para a obtenção do seu peso úmido, e em seguida foram colocados para secar em uma estufa de aeração forçada a $65^{\circ} \mathrm{C}$ até peso constante. Após a secagem, as amostras foram pesadas novamente para a medição do seu peso seco.

As amostras dos sacos plásticos foram secadas ao ar livre, destorroadas e peneiradas em peneira de $2 \mathrm{~mm}$. Subsequentemente, foram realizadas análises de $\mathrm{pH}$ e de condutividade elétrica. Para a análise de $\mathrm{pH}$, foram diluídos $10 \mathrm{~g}$ de solo em $25 \mathrm{ml}$ de água destilada $(1: 2,5)$, enquanto que para a condutividade elétrica foram diluídos $50 \mathrm{~g}$ de solo em $50 \mathrm{ml}$ de água destilada (1:1), com tempo de decantação de 60 minutos e de 24 horas, respectivamente (EMBRAPA, 2011). $\mathrm{O} \mathrm{pH}$ foi analisado por meio de um pHmetro de bancada da marca Tecnal, modelo Tec-3MP, enquanto que a condutividade foi medida em condutivímetro de bancada da marca Marconi, modelo MA 521. Com os valores obtidos foram calculadas as médias de cada um dos parâmetros por bloco. 


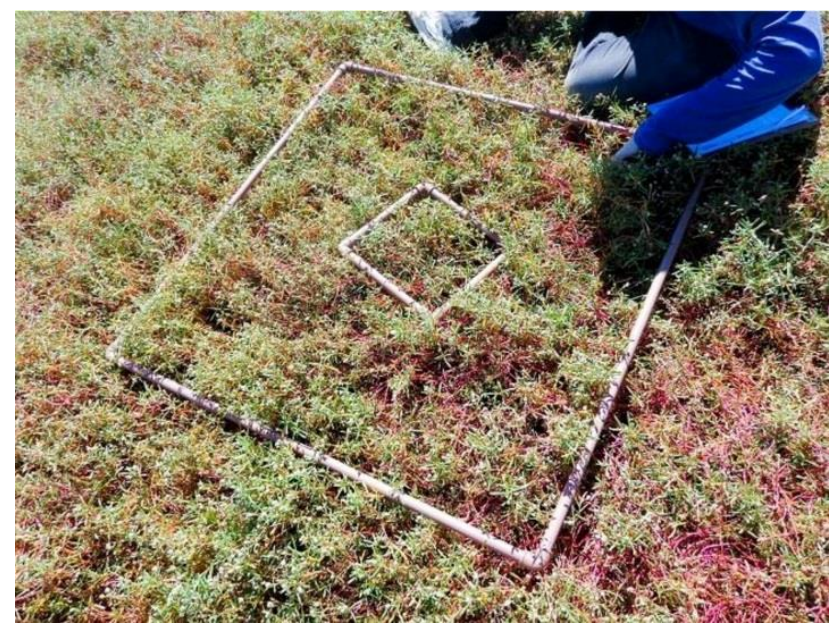

Figura 3. Contagem de plantas por espécie em área de $1 \mathrm{~m}^{2}$ delimitado por quadrado de canos de PVC.

\section{Resultados}

No geral, foram amostrados 6.573 indivíduos, divididos em 14 famílias e 37 espécies. A família com maior diversidade de espécies foi a Fabaceae com oito espécies, seguido de Malvaceae e Poaceae, com seis e cinco espécies, respectivamente. As famílias com mais indivíduos presentes foram Cyperaceae, sendo 2.225 indivíduos de duas espécies, Amaranthaceae com 2.132 indivíduos divididos em duas espécies e Malvaceae com 1.026 indivíduos distribuídos em 6 espécies, representando cerca de $80 \%$ dos espécimes amostrados (Tabela 1).

As espécies Cyperus rotundus L., Blutaparon vermiculare (L.) Mears e Malachra fasciata Jacq., foram as principais representantes de suas famílias, representando a quase totalidade dos indivíduos amostrados dessas (5.253 indivíduos). Vale ressaltar que essas três espécies, além de serem as espécies mais representativas no geral, foram encontradas em todas as amostragens realizadas, assim como as espécies Sesuvium portulacastrum (L.) L. e Ipomoea asarifolia (Desr.) Roem. \& Schult., entretanto com um total de indivíduos bem inferior. Na primeira coleta da quadra chuvosa, a espécie Blutaparon vermiculare foi a espécie mais ocorrente em ambas as áreas, assim como na coleta realizada na estação seca, enquanto que nas duas coletas realizadas na segunda coleta da quadra chuvosa, a espécie mais ocorrente foi Cyperus rotundus.

$\mathrm{Na}$ coleta realizada na área 1 durante $\mathrm{o}$ final da quadra chuvosa (Tabela 2), as espécies que tiveram maior frequência absoluta e relativa foram as espécies Blutaparon vermiculare, Malachra fasciata, Sesuvium portulacastrum, Sida rhombifolia L., Eragrostis plana Nees, Cyperus rotundus e Chloris barbata Sw., nessa ordem, enquanto em relação à densidade absoluta e relativa, as espécies com os valores maiores foram Blutaparon vermiculare, Eragrostis plana, Malachra fasciata, Cyperus rotundus, Sida rhombifolia, Sesuvium portulacastrum e Chloris barbata. Entretanto, embora sejam representativas no contexto geral, as espécies Eragrostis plana e Sida rhombifolia se concentraram preferencialmente no bloco 6 , no qual a condutividade elétrica do solo foi a menor da área $\left(0,31 \mathrm{dS} \quad \mathrm{m}^{-1}\right), \quad \mathrm{e}$ a espécie Sesuvium portulacastrum se concentrou preferencialmente no bloco 1 , no qual a condutividade elétrica do solo teve o seu maior valor registrado $(10,88 \mathrm{dS}$ $\mathrm{m}^{-1}$ ) e maior umidade no solo, enquanto a espécie Blutaparon vermiculare teve uma distribuição ampla na área inteira (Figura 4).

$\mathrm{Na}$ coleta realizada no pico da quadra chuvosa, Blutaparon vermiculare, Cyperus rotundus, Sesuvium portulacastrum, Malachra fasciata, Physalis angulata L., Paspalum ligulare Nees, Sesbania exasperata Kunth., Sida rhombifolia e Ipomoea asarifolia obtiveram os maiores valores de frequência absoluta e relativa, enquanto para os parâmetros densidade absoluta e relativa as espécies Blutaparon vermiculare, Malachra fasciata, Cyperus rotundus, Sesuvium portulacastrum, Sida rhombifolia e Paspalum ligulare foram as mais representativas (Tabela 2). Assim como na coleta realizada no final da quadra chuvosa, observa-se na Figura 5, que a espécie Blutaparon vermiculare se distribuiu amplamente em toda a área, assim como a espécie Sesuvium portulacastrum se concentrou novamente no bloco 1, que novamente obteve os maiores valores de condutividade elétrica $\left(16,22 \mathrm{dS} \mathrm{m}^{-1}\right)$. A espécie Paspalum ligulare e novamente a espécie Sida rhombifolia foram as espécies mais representativas no bloco 6 , que teve a menor

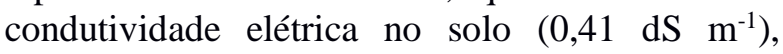
sendo este bloco também o que registrou a maior riqueza de espécies (14 espécies). 
Tabela 1. Espécies vegetais das áreas salinizadas do perímetro irrigado Curu-Recuperação, Pentecoste-CE, com as respectivas quantidades de indivíduos amostrados de cada espécie. Ch. 1. Primeira coleta da quadra chuvosa, realizada no final da estação chuvosa (maio/2016); Ch. 2. Segunda coleta da quadra chuvosa, realizada no pico da estação chuvosa (março/2017); Seca. Coleta da estação seca (outubro/2016).

\begin{tabular}{|c|c|c|c|c|c|}
\hline \multirow{2}{*}{ Famílias/Espécies } & \multicolumn{3}{|c|}{ Área 1} & \multicolumn{2}{|c|}{ Área 2} \\
\hline & Ch. 1 & Ch. 2 & Seca & Ch. 1 & Ch. 2 \\
\hline \multicolumn{6}{|l|}{ Aizoaceae (2) } \\
\hline Sesuvium portulacastrum (L.) L. & 75 & 84 & 54 & 16 & 2 \\
\hline Trianthema portulacastrum L. & - & - & - & - & 31 \\
\hline \multicolumn{6}{|l|}{ Amaranthaceae (2) } \\
\hline Alternanthera tenella Colla & 5 & - & - & 1 & - \\
\hline Blutaparon vermiculare (L.) Mears & 626 & 418 & 440 & 511 & 131 \\
\hline \multicolumn{6}{|l|}{ Apocynaceae (2) } \\
\hline Calotropis procera (Aiton) W.T.Aiton & - & 1 & 1 & - & 2 \\
\hline Cryptostegia madagascariensis Bojer & 1 & 2 & - & 4 & 1 \\
\hline \multicolumn{6}{|l|}{ Commelinaceae (1) } \\
\hline Commelina benghalensis L. & 1 & - & - & - & - \\
\hline \multicolumn{6}{|l|}{ Convolvulaceae (2) } \\
\hline Ipomoea asarifolia (Desr.) Roem. \& Schult. & 13 & 11 & 5 & 1 & 3 \\
\hline Ipomoea pes-caprae (L.) R.Br. & - & 1 & - & - & - \\
\hline \multicolumn{6}{|l|}{ Cucurbitaceae (1) } \\
\hline Cucumis anguria $\mathrm{L}$. & - & 2 & - & - & - \\
\hline \multicolumn{6}{|l|}{ Cyperaceae (2) } \\
\hline Cyperus rotundus $\mathrm{L}$. & 141 & 752 & 115 & 171 & 1009 \\
\hline Cyperus articulatus $\mathrm{L}$. & 18 & - & - & 16 & 3 \\
\hline \multicolumn{6}{|l|}{ Fabaceae (8) } \\
\hline Crotalaria retusa $\mathrm{L}$. & 1 & - & - & - & - \\
\hline Macroptilium lathyroides (L.) Urb. & - & - & - & 2 & - \\
\hline Desmanthus virgatus (L.) Willd & - & 8 & 1 & 9 & 2 \\
\hline Parkinsonia aculeata L. & 1 & - & - & - & - \\
\hline Senna obtusifolia (L.) H.S.Irwin \& Barneby & 3 & - & - & - & - \\
\hline Sida rhombifolia $\mathrm{L}$. & 90 & 83 & - & - & - \\
\hline Tephrosia egregia Sandwith & - & - & - & 2 & - \\
\hline Sesbania exasperata Kunth. & - & 18 & - & - & 10 \\
\hline \multicolumn{6}{|l|}{ Lamiaceae (2) } \\
\hline Mesosphaerum suaveolens (L.) Kuntze & 22 & 3 & - & - & - \\
\hline Ruellia geminiflora Kunth & - & - & - & 35 & - \\
\hline \multicolumn{6}{|l|}{ Malvaceae (6) } \\
\hline Malachra fasciata Jacq. & 210 & 515 & 24 & 33 & 151 \\
\hline Melochia pyramidata $\mathrm{L}$. & 15 & 5 & - & 2 & 13 \\
\hline Malvastrum coromandelianum Garcke & 23 & - & 2 & 4 & - \\
\hline Sidastrum micranthum (A.St.-Hil.) Fryxell & 1 & - & - & - & - \\
\hline Waltheria communis A. St.-Hil. & 2 & 2 & - & - & - \\
\hline Wissadula amplissima (L.) R.E.Fr. & 8 & 12 & 3 & 1 & - \\
\hline \multicolumn{6}{|l|}{ Molluginaceae (1) } \\
\hline Mollugo verticillata $\mathrm{L}$. & - & 7 & - & - & - \\
\hline \multicolumn{6}{|l|}{ Poaceae (5) } \\
\hline Chloris barbata $\mathrm{Sw}$. & 64 & 21 & - & 1 & 1 \\
\hline Dactyloctenium aegyptium (L.) Willd. & 11 & 19 & - & 53 & - \\
\hline Eragrostis plana Nees & 226 & - & - & - & - \\
\hline Echinochloa crus-pavonis (Kunth) Schult. & - & 7 & - & - & 18 \\
\hline Paspalum ligulare Nees & - & 56 & - & 24 & - \\
\hline \multicolumn{6}{|l|}{ Phyllanthaceae (1) } \\
\hline Phyllantus tenellus Roxb. & - & 16 & - & - & 1 \\
\hline \multicolumn{6}{|l|}{ Solanaceae (2) } \\
\hline Physalis angulata $\mathrm{L}$. & - & 41 & - & - & 7 \\
\hline Solanum agrarium Sendtn. & - & 3 & - & - & - \\
\hline
\end{tabular}


Tabela 2. Espécies vegetais da área 1 do perímetro irrigado Curu-Recuperação, Pentecoste-CE e seus respectivos parâmetros fitossociológicos estimados. Fa. Frequência absoluta; Fr. Frequência relativa (\%); Da. Densidade absoluta (ind. $\mathrm{m}^{-2}$ ); Dr. dominância relativa (\%).

\begin{tabular}{|c|c|c|c|c|c|c|c|c|c|c|c|c|}
\hline \multirow{2}{*}{ Espécies } & \multicolumn{4}{|c|}{ Área 1 - Chuva 1} & \multicolumn{4}{|c|}{ Área 1 - Chuva 2} & \multicolumn{4}{|c|}{ Área 1 - Seca } \\
\hline & $\mathbf{F a}$ & Fr & Da & Dr & $\mathbf{F a}$ & Fr & Da & Dr & $\mathbf{F a}$ & Fr & Da & Dr \\
\hline Sesuvium portulacastrum & 20,41 & 7,69 & 1,53 & 4,82 & 24,49 & 8,39 & 1,71 & 4,01 & 12,24 & 9,84 & 1,10 & 8,37 \\
\hline Alternanthera tenella & 6,12 & 2,31 & 0,10 & 0,32 & - & - & - & - & - & - & - & - \\
\hline Blutaparon vermiculare & 71,43 & 26,92 & 12,78 & 40,21 & 61,22 & 20,98 & 8,53 & 19,96 & 65,31 & 52,46 & 8,98 & 68,22 \\
\hline Calotropis procera & - & - & - & - & 2,04 & 0,70 & 0,02 & 0,05 & 2,04 & 1,64 & 0,02 & 0,16 \\
\hline Cryptostegia madagascariensis & 2,04 & 0,77 & 0,02 & 0,06 & 4,08 & 1,40 & 0,04 & 0,10 & - & - & - & - \\
\hline Commelina benghalensis & 2,04 & 0,77 & 0,02 & 0,06 & - & - & - & - & - & - & - & - \\
\hline Ipomoea asarifolia & 8,16 & 3,08 & 0,27 & 0,83 & 16,33 & 5,59 & 0,22 & 0,53 & 8,16 & 6,56 & 0,10 & 0,78 \\
\hline Ipomoea pes-caprae & - & - & - & - & 2,04 & 0,70 & 0,02 & 0,05 & - & - & - & - \\
\hline Cucumis anguria & - & - & - & - & 4,08 & 1,40 & 0,04 & 0,10 & - & - & - & - \\
\hline Cyperus rotundus & 18,27 & 6,92 & 2,88 & 9,06 & 34,69 & 11,89 & 15,35 & 35,91 & 20,41 & 16,39 & 2,35 & 17,83 \\
\hline Cyperus articulatus & 4,08 & 1,54 & 0,37 & 1,16 & - & - & - & - & - & - & - & - \\
\hline Crotalaria retusa & 2,04 & 0,77 & 0,02 & 0,06 & - & - & - & - & - & - & - & - \\
\hline Desmanthus virgatus & - & - & - & - & 4,08 & 1,40 & 0,16 & 0,38 & 2,04 & 1,64 & 0,02 & 0,16 \\
\hline Parkinsonia aculeata & 2,04 & 0,77 & 0,02 & 0,06 & - & - & - & - & - & - & - & - \\
\hline Senna obtusifolia & 4,08 & 1,54 & 0,06 & 0,19 & - & - & - & - & - & - & - & - \\
\hline Sida rhombifolia & 18,37 & 6,92 & 1,84 & 5,78 & 16,33 & 5,59 & 1,69 & 3,96 & - & - & - & - \\
\hline Sesbania exasperata & - & - & - & - & 18,37 & 6,29 & 0,37 & 0,86 & - & - & - & - \\
\hline Mesosphaerum suaveolens & 4,08 & 1,54 & 0,45 & 1,41 & 2,04 & 0,70 & 0,06 & 0,14 & - & - & - & - \\
\hline Malachra fasciata & 24,49 & 9,23 & 4,29 & 13,49 & 24,49 & 8,39 & 10,51 & 24,59 & 8,16 & 6,56 & 0,49 & 3,72 \\
\hline Melochia pyramidata & 14,29 & 5,38 & 0,31 & 0,96 & 4,08 & 1,40 & 0,10 & 0,24 & - & - & - & - \\
\hline Malvastrum coromandelianum & 10,20 & 3,85 & 0,47 & 1,48 & - & - & - & - & 2,04 & 1,64 & 0,04 & 0,31 \\
\hline Sidastrum micranthum & 2,04 & 0,77 & 0,02 & 0,06 & - & - & - & - & - & - & - & - \\
\hline Waltheria communis & 2,04 & 0,77 & 0,04 & 0,13 & 4,08 & 1,40 & 0,04 & 0,10 & - & - & - & - \\
\hline Wissadula amplíssima & 8,16 & 3,08 & 0,16 & 0,51 & 4,08 & 1,40 & 0,24 & 0,57 & 4,08 & 3,28 & 0,06 & 0,47 \\
\hline Mollugo verticillata & - & - & - & - & 2,04 & 0,70 & 0,14 & 0,33 & - & - & - & - \\
\hline Chloris barbata & 16,33 & 6,15 & 1,31 & 4,11 & 8,16 & 2,80 & 0,43 & 1,00 & - & - & - & - \\
\hline Dactyloctenium aegyptium & 6,12 & 2,31 & 0,22 & 0,71 & 6,12 & 2,10 & 0,39 & 0,91 & - & - & - & - \\
\hline Eragrostis plana & 18,37 & 6,92 & 4,61 & 14,52 & - & - & - & - & - & - & - & - \\
\hline Echinochloa crus-pavonis & - & - & - & - & 2,04 & 0,70 & 0,14 & 0,33 & - & - & - & - \\
\hline Paspalum ligulare & - & - & - & - & 20,41 & 6,99 & 1,14 & 2,67 & - & - & - & - \\
\hline Phyllantus tenellus & - & - & - & - & 10,20 & 3,50 & 0,33 & 0,76 & - & - & - & - \\
\hline Physalis angulata & - & - & - & - & 22,45 & 7,69 & 0,98 & 2,29 & - & - & - & - \\
\hline Solanum agrarium & - & - & - & - & 2,04 & 0,70 & 0,06 & 0,14 & - & - & - & - \\
\hline
\end{tabular}

A estação seca revelou a menor riqueza de espécies (9 espécies), no entanto, as espécies com maiores frequências absoluta e relativa foram Blutaparon vermiculare, Cyperus rotundus, Sesuvium portulacastrum, Malachra fasciata e Ipomoea asarifolia (Tabela 2). Assim como nas demais coletas realizadas na área, a espécie Blutaparon vermiculare teve ampla distribuição e a espécie Sesuvium portulacastrum se concentrou nos blocos com maior condutividade elétrica no solo, blocos 1 e $2\left(17,59 \mathrm{dS} \mathrm{m}^{-1}\right.$ e 10,22 dS m-1, respectivamente), contudo, poucos registros foram feitos no bloco 6, a menor condutividade elétrica do solo $\left(0,88 \mathrm{dS} \mathrm{m}^{-1}\right)$, sendo Ipomoea asarifolia a espécie mais representativa (Figura 6). 


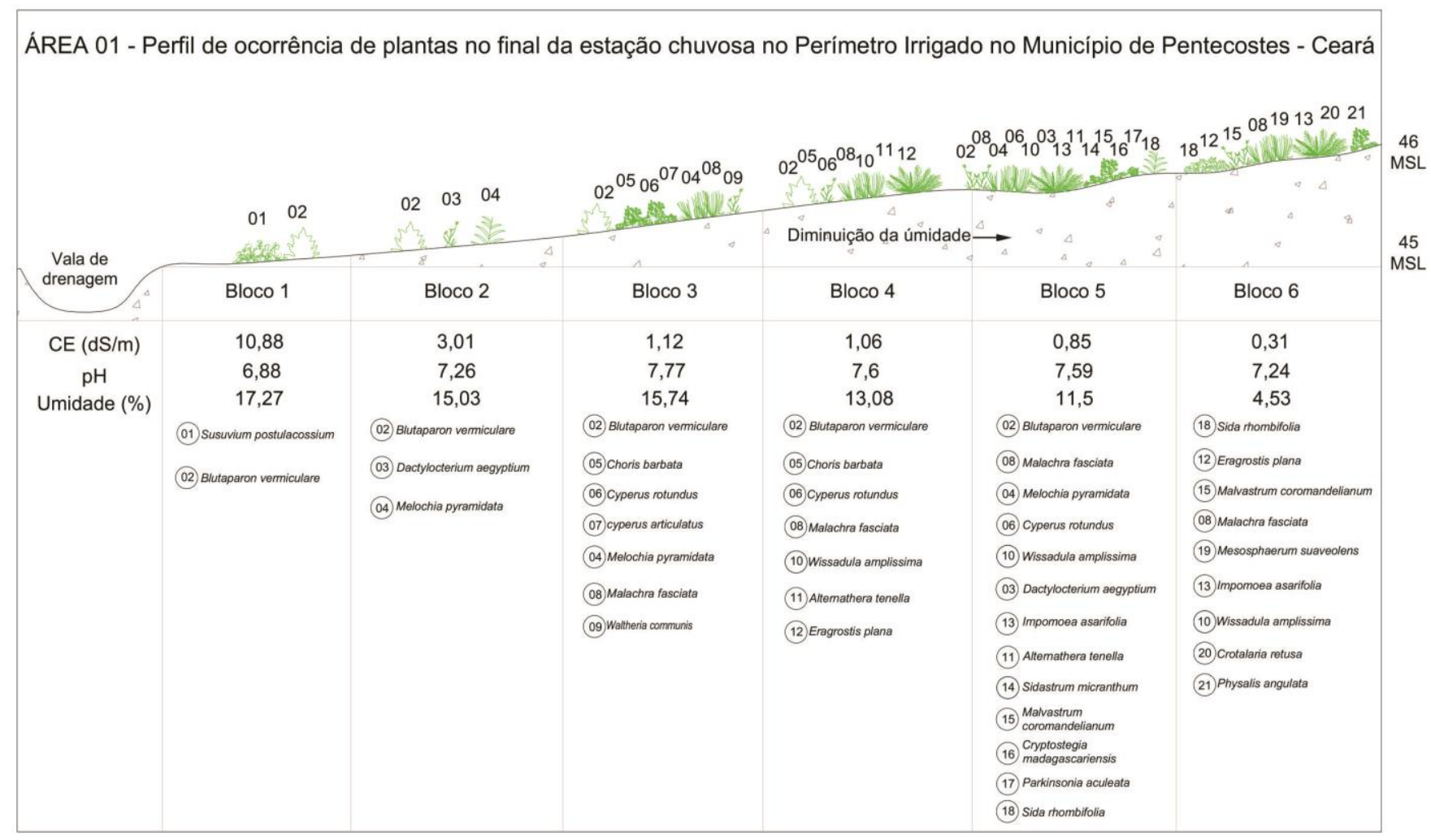

Figura 4. Perfil de ocorrência de espécies vegetais nos blocos da área 1 durante a primeira coleta, realizada no final da estação chuvosa (maio/2016), associada aos parâmetros condutividade elétrica (CE), pH e umidade do solo, no perímetro irrigado Curu-Recuperação no município de Pentecoste-CE.

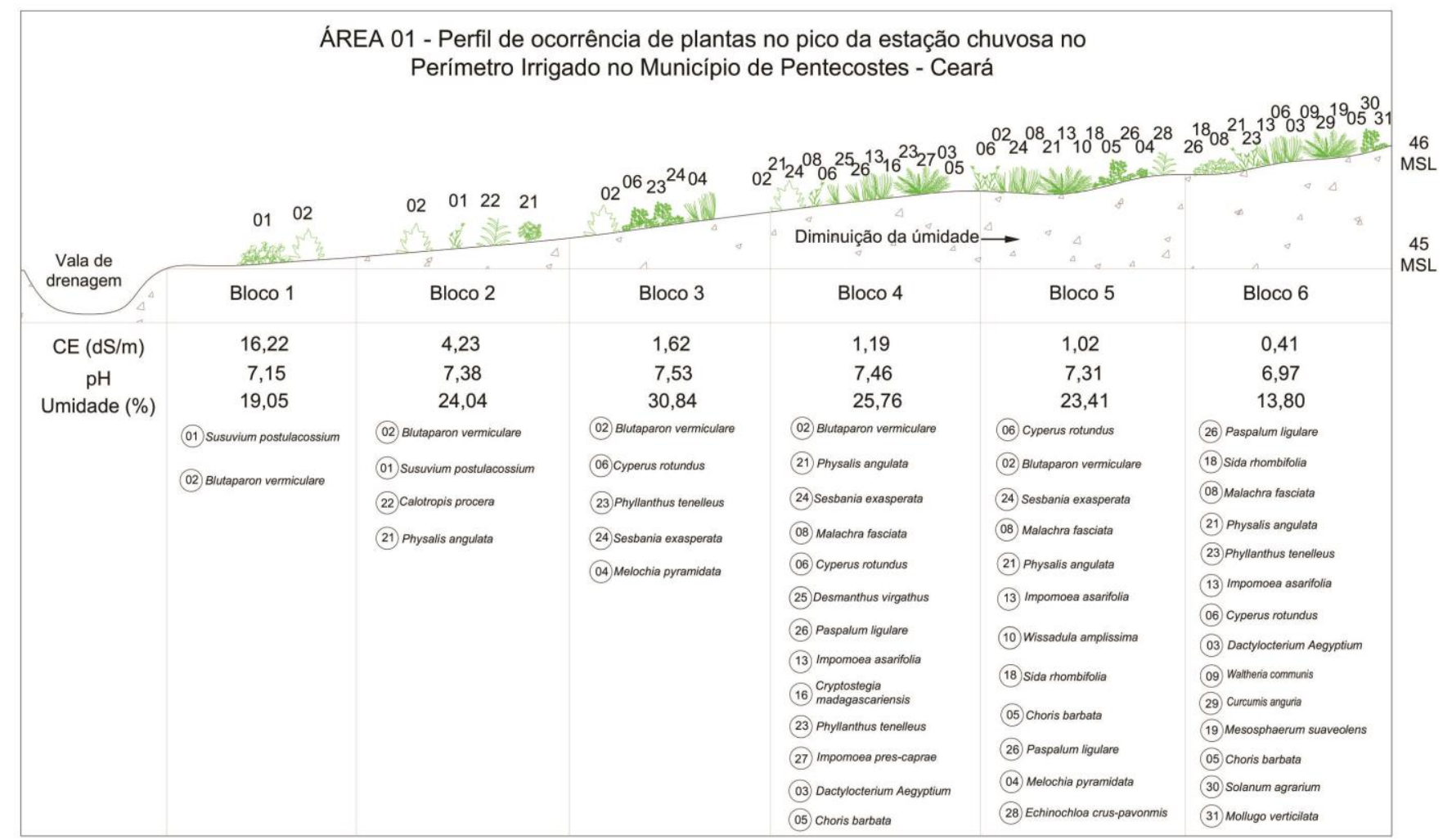

Figura 5. Perfil de ocorrência de espécies vegetais nos blocos da área 1 durante a coleta segunda, coleta de chuva, realizada no pico da estação chuvosa (março/2017), associada aos parâmetros condutividade elétrica (CE), $\mathrm{pH}$ e umidade do solo, no perímetro irrigado Curu-Recuperação no município de Pentecoste-CE. 


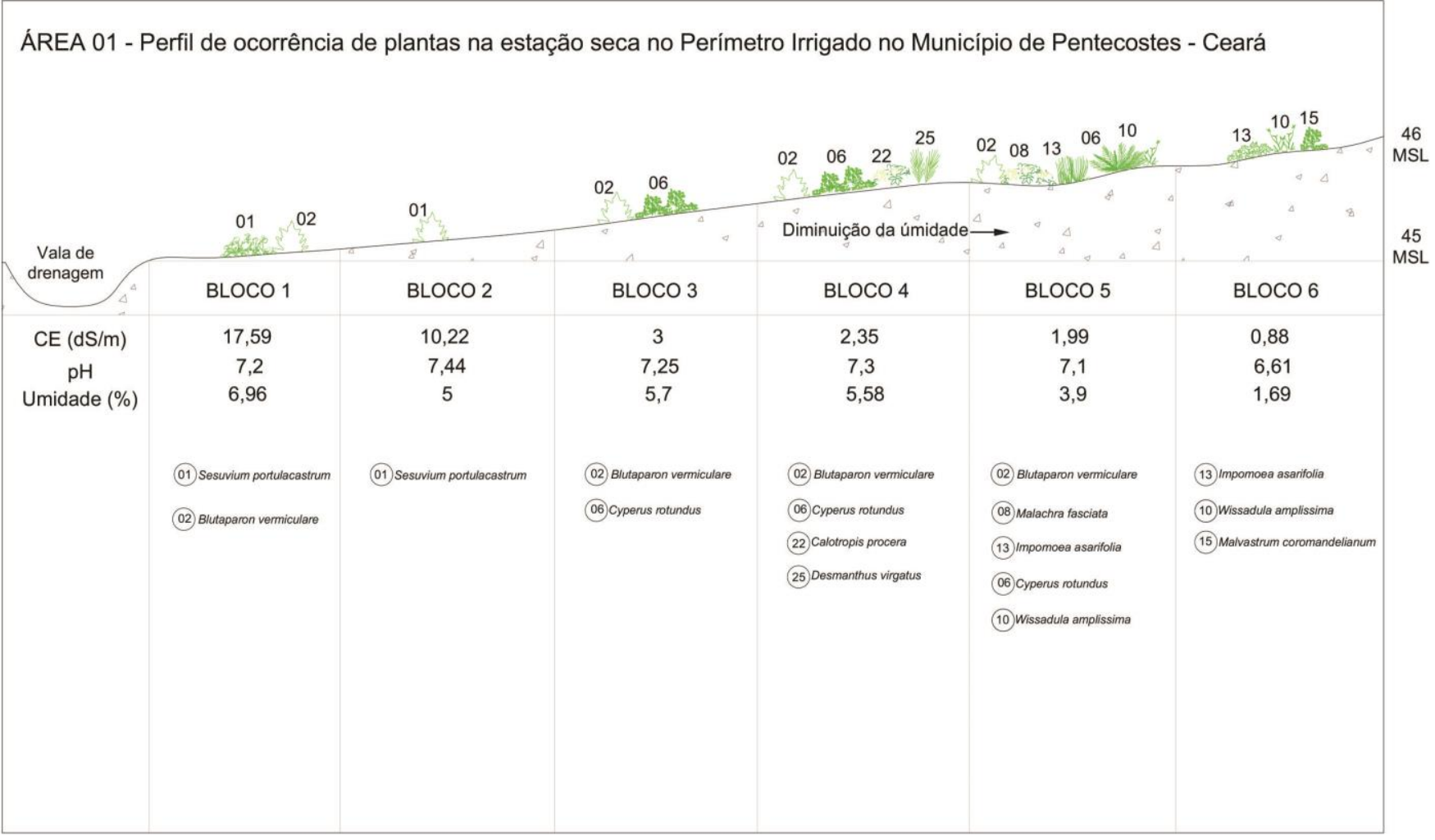

Figura 6. Perfil de ocorrência de espécies vegetais nos blocos da área 1 durante a estação seca (outubro/2016), associada aos parâmetros condutividade elétrica (CE), pH e umidade do solo, no perímetro irrigado Curu-Recuperação no município de Pentecoste-CE.

A área 2 no final da quadra chuvosa verificou-se que as espécies Blutaparon vermiculare, Cyperus rotundus e Malachra fasciata foram mais frequentes, seguidas das espécies Ruellia geminiflora Kunth, Paspalum ligulare, Desmanthus virgatus (L.) Willd, Malvastrum coromandelianum Garcke e Cyperus articulatus L., enquanto as espécies com maiores densidades foram Blutaparon vermiculare, Cyperus rotundus, Dactyloctenium aegyptium (L.) Willd., Ruellia geminiflora e Malachra fasciata (Tabela 3). Na Figura 7, nota-se uma uniformidade na distribuição das espécies na área, assim como na condutividade elétrica do solo dos blocos, com ampla distribuição da espécie Blutaparon vermiculare em todos os blocos.

A área 2 durante o pico da estação chuvosa foi a única coleta em que a espécie Blutaparon vermiculare não foi superior em frequências absoluta e relativa, sendo a espécie Cyperus rotundus a mais frequente, seguida das espécies Malachra fasciata, Blutaparon vermiculare, Physalis angulata, Sesbania exasperata, Melochia pyramidata L. e Echinochloa crus-pavonis (Kunth) Schult. As espécies com maiores densidades foram Cyperus rotundus, Malachra fasciata, Blutaparon vermiculare e Trianthema portulacastrum L. (Tabela 3), destacando-se que todos os indivíduos da espécie Trianthema portulacastrum ocorreram apenas em uma parcela do bloco $5(\mathrm{CE}=1,3 \mathrm{dS}$ $\left.\mathrm{m}^{-1}\right)$ (Figura 8).

A área 1 durante $o$ pico da estação chuvosa (Tabela 4) foi a que obteve a maior riqueza de espécies (24 esp.), e a coleta realizada na mesma área durante a estação seca foi a com menor riqueza ( 9 esp.), como já citado. Embora a área 1 no pico da estação chuvosa tenha obtido o maior valor de riqueza, a coleta realizada no final da estação chuvosa obteve as maiores diversidades para o índice de Shannon. A área 2 no pico da quadra chuvosa, na qual a riqueza de espécies foi praticamente o dobro da área 1 na estação seca, obteve valores semelhantes de diversidade à área com menor valor de riqueza.

Os resultados de similaridade realizados por meio do índice de Sorensen apontam uma maior similaridade entre as coletas realizadas no pico e no final da estação chuvosa na área 1 $(0,70)$, seguido de uma maior similaridade entre as coletas realizadas no pico e no final da estação chuvosa na área $2(0,65)$. A análise de Cluster por UPGMA corrobora com a maior similaridade encontrada entre as coletas realizadas na quadra chuvosa na área 1 e as coletas realizadas na quadra chuvosa na área 2 entre si, bem como, uma dissimilaridade dessas em relação à coleta realizada na estação seca na área 1 (Figura 9). 


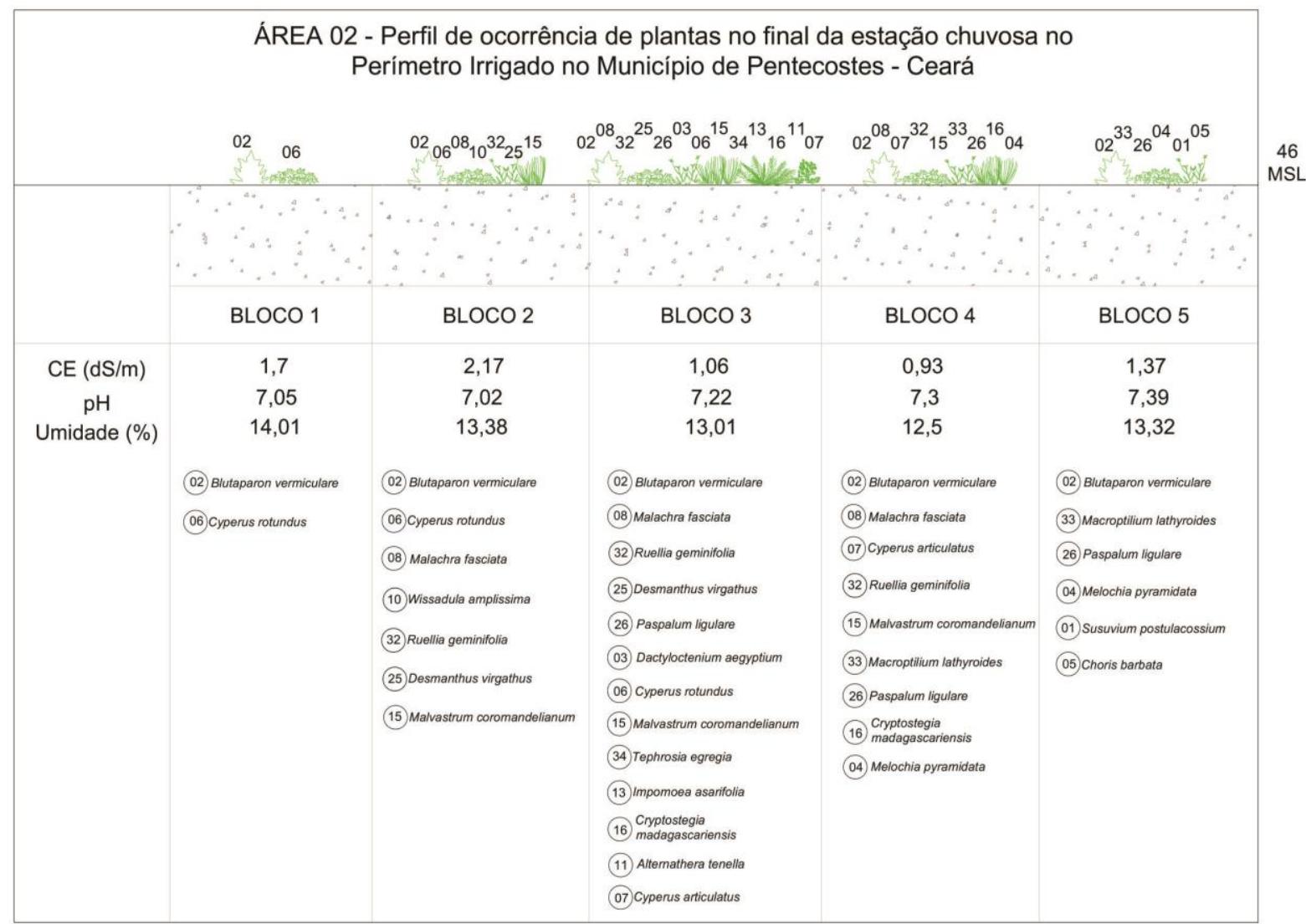

Figura 7. Perfil de ocorrência de espécies vegetais nos blocos da área 2 durante a primeira coleta de chuva, realizada no final da estação chuvosa (maio/2016), associada aos parâmetros condutividade elétrica (CE), pH e umidade do solo, no perímetro irrigado Curu-Recuperação no município de Pentecoste-CE.

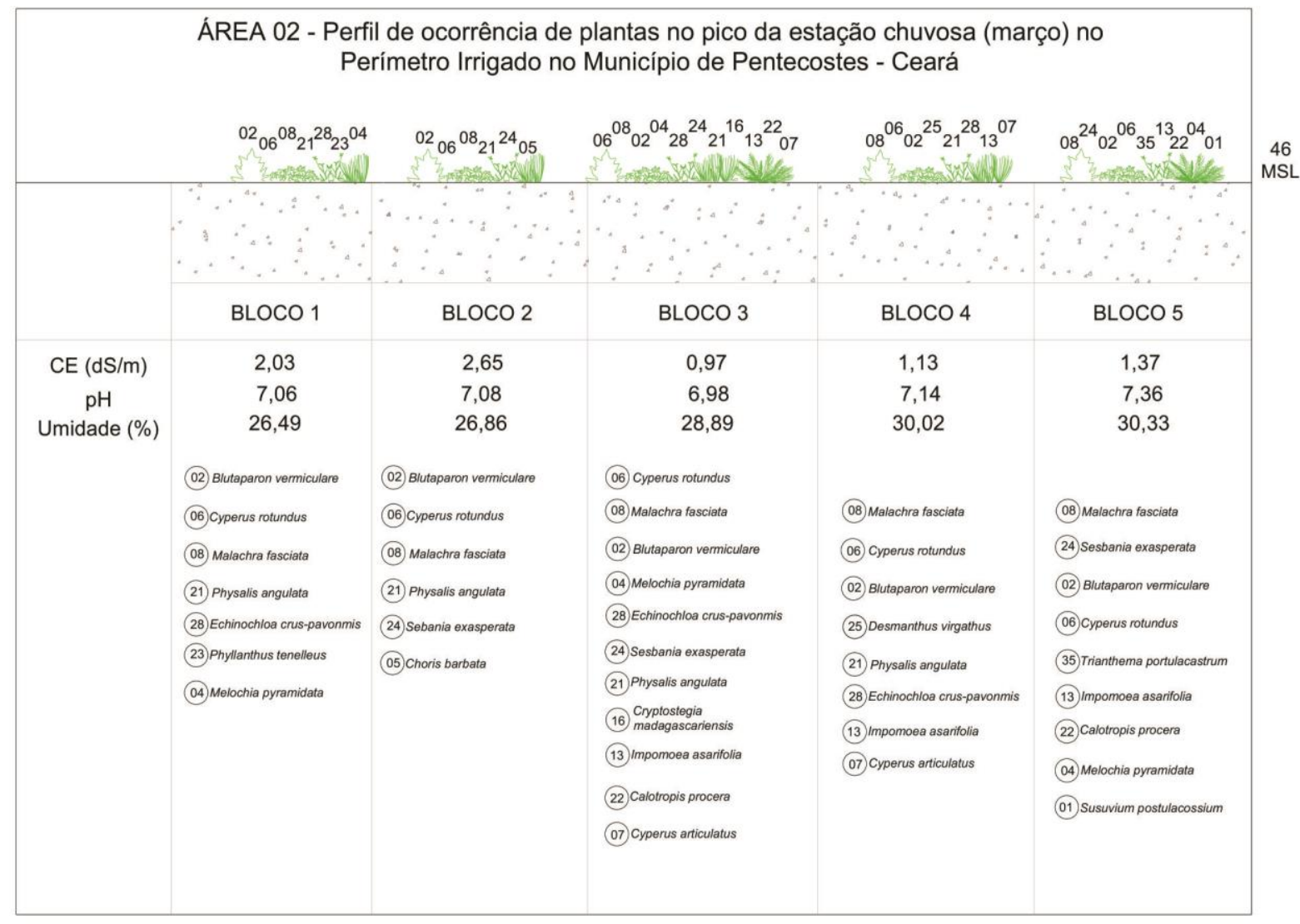

Figura 8. Perfil de ocorrência de espécies vegetais nos blocos da área 2 durante a segunda coleta de chuva, realizada no pico da estação chuvosa (março/2017), associada aos parâmetros condutividade elétrica (CE), pH e umidade do solo, no perímetro irrigado Curu-Recuperação no município de Pentecoste-CE. 
Tabela 3. Riqueza (Sorensen) e diversidade (Shannon) de plantas por amostragem realizada em áreas salinizadas do perímetro irrigado Curu-Recuperação, Pentecoste-CE. Chuva 1. Primeira coleta da quadra chuvosa, realizada no final da estação chuvosa (maio/2016); Chuva 2. Segunda coleta da quadra chuvosa, realizada no pico da estação chuvosa (março/2017); Seca. Coleta da estação seca (outubro/2016).

\begin{tabular}{lccccc}
\hline \multirow{2}{*}{\multicolumn{1}{c}{ Índices }} & \multicolumn{3}{c}{ Área 1 } & \multicolumn{2}{c}{ Área 2 } \\
\cline { 2 - 6 } & Chuva 1 & Chuva 2 & Seca & Chuva 1 & Chuva 2 \\
\hline Sorensen (S) & 22 & 24 & 9 & 18 & 16 \\
Shannon (H') & 1,96 & 1,19 & 1,00 & 1,46 & 1,03 \\
\hline
\end{tabular}

Tabela 4. Espécies da área 2 do perímetro irrigado Curu-Recuperação, Pentecoste-CE e seus respectivos parâmetros fitossociológicos estimados. Fa. Frequência absoluta; Fr. Frequência relativa (\%); Da. Densidade absoluta (ind. $\mathrm{m}^{-2}$ ); Dr. Dominância relativa (\%).

\begin{tabular}{lccccccccc}
\hline \multirow{2}{*}{ Espécies } & \multicolumn{3}{c}{ Área 2 - Chuva 1 } & \multicolumn{5}{c}{ Área 2 - Chuva 2 } \\
\cline { 2 - 9 } & Fa & Fr & Da & Dr & Fa & Fr & Da & Dr \\
\hline Sesuvium portulacastrum & 4,17 & 1,39 & 0,64 & 1,81 & 4,17 & 1,10 & 0,08 & 0,14 \\
Trianthema portulacastrum & - & - & - & - & 4,17 & 1,10 & 1,24 & 2,23 \\
Alternanthera tenella & 4,17 & 1,39 & 0,04 & 0,11 & - & - & - & - \\
Blutaparon vermiculare & 95,83 & 31,94 & 20,44 & 57,67 & 70,83 & 18,68 & 5,24 & 9,42 \\
Calotropis procera & - & - & - & - & 8,33 & 2,20 & 0,08 & 0,14 \\
Cryptostegia madagascariensis & 8,33 & 2,78 & 0,16 & 0,45 & 4,17 & 1,10 & 0,04 & 0,07 \\
Ipomoea asarifolia & 4,17 & 1,39 & 0,04 & 0,11 & 12,50 & 3,30 & 0,12 & 0,22 \\
Cyperus rotundus & 41,67 & 13,89 & 6,84 & 19,30 & 83,33 & 21,98 & 40,36 & 72,54 \\
Cyperus articulatus & 12,50 & 4,17 & 0,64 & 1,81 & 8,33 & 2,20 & 0,12 & 0,22 \\
Macroptilium lathyroides & 8,33 & 2,78 & 0,08 & 0,23 & - & - & - & - \\
Desmanthus virgatus & 12,50 & 4,17 & 0,36 & 1,02 & 8,33 & 2,20 & 0,08 & 0,14 \\
Tephrosia egregia & 4,17 & 1,39 & 0,08 & 0,23 & - & - & - & - \\
Sesbania exasperata & - & - & - & - & 25,00 & 6,59 & 0,40 & 0,72 \\
Ruellia geminiflora & 16,67 & 5,56 & 1,40 & 3,95 & - & - & - & - \\
Malachra fasciata & 33,33 & 11,11 & 1,32 & 3,72 & 79,17 & 20,88 & 6,04 & 10,86 \\
Melochia pyramidata & 8,33 & 2,78 & 0,08 & 0,23 & 20,83 & 5,49 & 0,52 & 0,93 \\
Malvastrum coromandelianum & 12,50 & 4,17 & 0,16 & 0,45 & - & - & - & - \\
Wissadula amplíssima & 4,17 & 1,39 & 0,04 & 0,11 & - & - & - & - \\
Chloris barbata & 4,17 & 1,39 & 0,04 & 0,11 & 4,17 & 1,10 & 0,04 & 0,07 \\
Dactyloctenium aegyptium & 8,33 & 2,78 & 2,12 & 5,98 & - & - & - & - \\
Echinochloa crus-pavonis & - & - & - & - & 16,67 & 4,40 & 0,72 & 1,29 \\
Paspalum ligulare & 16,67 & 5,56 & 0,96 & 2,71 & - & - & - & - \\
Phyllantus tenellus & - & - & - & - & 4,17 & 1,10 & 0,04 & 0,07 \\
Physalis angulata & - & - & - & - & 25,00 & 6,59 & 0,52 & 0,93 \\
\hline
\end{tabular}

\section{Discussão}

A riqueza de espécies herbáceas encontradas nas áreas experimentais do perímetro irrigado CuruRecuperação demonstrou ser superior (37 espécies) a levantamentos realizados recentemente em áreas agrícolas, onde em média foram identificadas 20 espécies espontâneas (Cunha et al., 2014, Rodrigues et al., 2016, Rodrigues et al.,
2017). Tratando-se de halófitas em áreas do sertão nordestino, Costa e Herrera (2016a) em sua revisão caracterizaram 16 espécies classificadas como halófitas. Dentre essas, pode-se destacar as espécies camefíticas Blutaparon vermiculare e Sesuvium portulacastrum, espécies encontradas em ambas as áreas experimentais. 


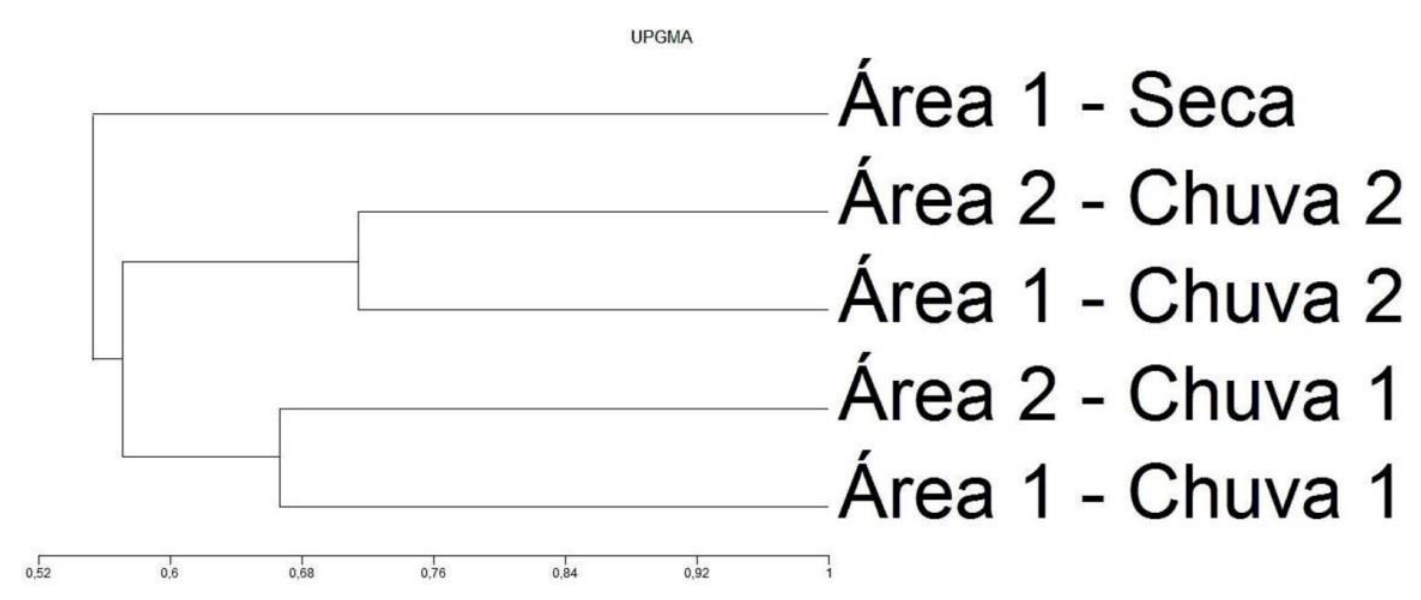

Figura 9. Análise Cluster por UPGMA entre as amostragens realizadas nas áreas experimentais do perímetro irrigado Curu-Recuperação por meio do índice de Sorensen. Chuva 1. Coleta realizada no final da quadra chuvosa (maio/2016); Chuva 2. Coleta realizada no pico da quadra chuvosa (março/2107); Seca. Coleta realizada na estação seca (outubro/2016).

De acordo com o IBGE (2012), a vegetação da Caatinga é classificada como savana estépica, guardando características na composição florística com áreas da Argentina, onde espécies ocorrentes nas áreas experimentais tais como Blutaparon vermiculare, Sesuvium portulacastrum, Malvastrum coromandelianum e Chloris barbata foram registradas em áreas com o solo salinizado (Cantero et al., 2016). As espécies Chloris barbata, Blutaparon vermiculare e Sesuvium portulacastrum também são citadas por Flores-Olvera et al. (2016) como ocorrentes em áreas com elevado teor de sais no solo no México, assim como as espécies Ipomoea pes-caprae, Cyperus articulatus, Desmanthus virgatus e Dactyloctenium aegyptium. No Estado de Gujarate, na Índia, as espécies Ipomoea pescaprae, Sesuvium portulacastrume e Trianthema portulacastrum foram caracterizadas como plantas halófitas e registradas na revisão de Salvi et al. (2017).

De acordo com Moro et al. (2015), as espécies Ipomoea pes-caprae, Ipomoea asarifolia, Sesuvium portulacastrum e Blutaparon vermiculare são plantas presentes na região costeira do Ceará, em áreas como o campo praiano e as dunas semifixas e móveis, onde a ação das ondas do mar e do vento resultam na maresia e em sprays marinhos, que tornam o ambiente salino. Os autores ainda relatam que as espécies Sesuvium portulacastrum e Blutaparon vermiculare ocorrem em regiões hipersalinas denominadas apicuns, regiões nas quais as altas taxas de evaporação associadas a alagamentos ocasionais geram áreas onde prevalecem condutividades elétricas de 123 a $220 \mathrm{dS} / \mathrm{m}^{-1}$ (Costa et al., 2009, Albuquerque et al., 2014).
Medina et al. (2008) também registraram as espécies Sesuvium portulacastrum, Trianthema portulacastrum e Ipomoea pes-caprae em áreas costeiras na costa caribenha da Venezuela, onde estas espécies apresentaram um elevado grau de suculência $(90,7 \%$ e $87,9 \%$, respectivamente), sendo esta é uma das estratégias adaptativas mais comuns em plantas resistentes ao estresse salino (García et al., 2008, Medina, 2016).

Tanto na área 1 como na área 2 (blocos 1 e 2) a presença destas plantas de consistência suculenta nos locais onde a condutividade elétrica (CE) e a umidade do solo foram as maiores (Figuras 4 a 8), são indicadoras biológicas de solos salinos (halófitas), as quais tendem a acumular água para compensar o excesso de concentração salina intracelular.

A espécie Blutaparon vermiculare é uma erva nativa não endêmica do Brasil que se distribui na costa brasileira desde o Maranhão, no nordeste do país, até o litoral do Estado de Santa Catarina, no Sul (Senna e Marchioretto, 2015). A revisão etnobotânica realizada por Medeiros e Albuquerque (2014) lista a espécie como uma planta com potencial comestível, podendo ser servida cozida com carnes e peixes. Os autores reportam ainda o potencial diurético da erva, bem como, a sua capacidade de estimular o apetite. Entretanto, o consumo desta halófita na dieta pelos brasileiros é incomum (Costa e Herrera, 2016b).

A espécie Blutaparon vermiculare pode ainda ser utilizada como forragem, assim como a espécie Sesuvium portulacastrum (Albuquerque et al., 2007; Sousa, 2010). Se tratando da espécie Sesuvium portulacastrum, a aplicação na vida humana é diversa, como na medicina popular, sendo a sua infusão utilizada no tratamento de 
gripe (Albuquerque et al., 2007), podendo ser utilizada ainda no preparo de sal vegetal nutritivo, uma vez que esta, se caracteriza por seu caule e folhas serem ricos em elementos $\mathrm{Ca}$, $\mathrm{Fe}$ e em caroteno (Corrêa, 1984; Medina et al., 2008; Lockande et al., 2009). Esta erva nativa conhecida popularmente como Beldroega-dapraia se distribui naturalmente por todo o litoral brasileiro e em todas as regiões continentais brasileiras cujo solo apresenta um alto teor de sais, ocorrendo nos domínios da Caatinga (Couto e Cardoso, 2017; Costa e Herrera (2016a).

Em regiões de apicuns, esta espécie se alterna na dominância com outras espécies halófitas e tolerantes, produz biomassa elevada em locais onde a salinidade é elevada (Sousa, 2010; Medina, 2016). No perímetro irrigado de Pentecoste, foi possível encontrar estas espécies associadas a outras famílias botânicas reconhecidas por apresentar exemplares halofíticos e tolerantes à salinidade como as famílias Convolvulacea, Fabaceae, Malvaceae e Poaceae (Tabelas 1 a 3 ). Estas plantas apresentam um amplo espectro de adaptações que as habilitam para crescer com êxito em habitats salinos, tais como a presença de pelos e tricomas na superfície foliar, principalmente como as encontradas, Malacra fasciata, Melochia piramidata e Eragrotis plana, que repelem a luz e auxiliam evitando a perda de água por transpiração (García et al., 2008; Ruiz et al., 2015).

Maior número de espécies aparece na área 1 , blocos 3 a 6 , e na área 2 , blocos 3 a 5 (Figuras 4 a 8 ) na medida que a umidade do solo diminui e também a condutividade elétrica, sendo o solo caraterizado como ligeiramente salino, no qual plantas muito sensíveis podem ser afetadas em seu crescimento (Pizarro, 1976; EMPRAPA, 2013) Trata-se de espécies que manifestam tolerância à salinidade (famílias Malvaceae e Convolvulaceae) ou então apresentam sensibilidade ao sal no solo como é o caso de algumas da família Poaceae (Senna obstusifolia e Sida rhombifolia).

Algumas pesquisas mostram que Senna obtusifolia e Ipomoea pes-caprae, apresentam propriedades tóxicas, provavelmente devido à presença de metabolitos secundários. A primeira tem utilidade no tratamento de úlcera, tendo também propriedades sedativas e analgésicas, enquanto a infusão da segunda pode ser ingerida para o tratamento de doenças hepáticas e reumatismo, podendo ainda ser utilizada na lavagem de pele acometida por dermatites e ulcerações (Albuquerque et al., 2007; Agra et al., 2008). As sementes da espécie Senna obtusifolia tem ainda antraquinonas, inclusive com várias já isoladas, como a emodina, que já foi utilizada como larvicida (Yang et al., 2003). Contudo, vale ressaltar que a ingestão das folhas desta leguminosa é tóxica para os bovinos, sendo uma das causas mais frequentes de intoxicação animal (Queiroz et al., 2012; Costa e Herrera, 2016a).

Embora não seja comum o seu registro em pesquisas e revisões envolvendo halófitas, as espécies Cyperus rotundus e Malachra fasciata foram encontradas na área experimental em locais com baixa condutividade elétrica no período chuvoso, chegando a quase desaparecer no período seco. Tais espécies foram registradas em áreas próximas a corpos d'água na cidade de Patos, sertão da Paraíba, no Nordeste brasileiro (Torres et al., 2016).

A Malachra fasciata é uma erva nativa e não endêmica do Brasil (Fernandes-Júnior, 2017), sendo conhecida pelo seu potencial anticancerígeno (Grabarczyk et al., 2015). Já a espécie Cyperus rotundus, é uma planta invasora exótica bastante ocorrente em áreas agrícolas irrigadas, sendo uma das principais espécies encontradas em campos de arroz asiáticos, crescendo preferencialmente nas margens dos corpos d'água (Rao et al., 2008; Lee et al., 2014; Cunha et al., 2014; Rodrigues et al., 2017). Caracteriza-se por ser uma espécie com considerável tolerância aos ambientes com substrato contaminado por metais tóxicos, podendo ser utilizada na fitorremediação destes (Mukhopadhyay, 2017).

A presença destas espécies em blocos onde a condutividade elétrica do solo ultrapassou os $2 \mathrm{dS} / \mathrm{m}^{-1}$ sugere um certo nível de tolerância destas espécies aos sais no solo, visto que esta condutividade elétrica já afeta a maioria das culturas, tais como o melão, feijão, batatadoce, batata-inglesa e pimentão (Bezerra, 2006). Embora a condutividade elétrica do solo para que este seja considerado salinizado seja de $4 \mathrm{dS} / \mathrm{m}^{-1}$ na maioria dos sistemas de classificação de solos, uma abordagem mais rígida, baseada na tolerância das culturas ao estresse salino, classifica solos com condutividade elétrica acima dos $2 \mathrm{dS} / \mathrm{m}^{-1}$ como ligeiramente salino (DNOCS, 1976; Richards, 1974; KotubyAmacher et al., 2000; EMBRAPA, 2013).

As espécies da família Apocynaceae Calotropis procera (Aiton) W.T. Aiton e Cryptostegia madagascariensis Bojer, foram registradas nas duas áreas experimentais, conquanto, a sua representatividade é pequena nestas. A baixa representatividade pode ser 
associada aos teores de salinidade presentes no solo e ao período das chuvas, sendo sua presença em menor número no período da estiagem.

Esses arbustos exóticos originários da ilha de Madagascar, na África, são considerados fitoinvasores na Caatinga nordestina (Andrade, 2013; Frosi et al., 2013). A Cryptostegia madagascariensis, conhecida popularmente como unha-do-cão, tem preferência por locais alagadiços, como margens de rios, onde formam maciços populacionais de alta densidade, onde impedem ou dificultam o desenvolvimento de outras espécies por limitação de recursos (Andrade, 2013; Sousa et al., 2016).

Esta fitoinvasora promove alterações na abundância e diversidade da comunidade de fungos micorrízicos arbusculares, assim como em propriedades do solo, como, por exemplo, o $\mathrm{pH}$, alterando as características do solo em questão e promovendo o crescimento desta planta em detrimento das espécies nativas (Souza et al., 2016; Souza et al., 2017). Calotropis procera por sua vez é uma espécie que compete vigorosamente com espécies naturais da Caatinga, sendo assim uma ameaça relevante à biodiversidade do bioma (Leão et al., 2011). Todavia, a alta adaptabilidade desta invasora possui um viés benéfico, visto que esta também possui tolerância a metais tóxicos, podendo ser utilizada na fitoextração do metal cádmio e na fitoestabilização de outros potenciais metais tóxicos, tais como chumbo, cromo e cobalto (Mukhopadhyay, 2017).

No estudo foi observado a presença de algumas espécies com baixa ocorrência e principalmente no pico das chuvas, em ambas as áreas estudadas (Figuras 5 e 8, bloco 4). É o caso de Physalis angulata.

A salinidade no solo, nessa época tende a diminuir pela lixiviação dos sais acumulados e pelo aumento da umidade no mesmo. Esta espécie prefere solos com salinidade imperceptível $\left(\mathrm{CE}=1,13-1,19 \mathrm{dS} \mathrm{m}^{-1}\right)$ que no pico das chuvas ficam bastante úmidos, daí as plantas são de consistência suculenta e de curto ciclo de vida, já que no fim do período chuvoso e na época seca desaparece tanto na área 1 como na área 2.

Em pesquisa realizada recentemente, Almeida Júnior et al. (2017) investigou o potencial anti-inflamatório da espécie Physalis angulata, obtendo resultados promissores na aplicação clínica desta no combate a inflamações intestinais. A espécie popularmente conhecida como Camapu pode ser consumida in natura, tem potencial larvicida e possui inúmeras aplicações fitofarmacológicas, como no tratamento de cancirnomas, e doenças renais, diminuindo a rejeição em transplantes e atacando alergias, dentre outras (Nnamani et al., 2009; Lucena et al., 2015). Porém, possui baixa produtividade em condições na qual o substrato apresenta concentração salina superior a $50 \mathrm{mM}$ de $\mathrm{NaCl}$ (Souza et al., 2007).

A diversidade de espécies encontradas nas amostragens realizadas de acordo com os índices calculados, foram pequenos em relação aos encontrados por Costa et al. (2009) em pesquisa realizada no semiárido nordestino.

Contudo, o índice de Shannon encontrado em trabalhos realizados por Mętrak et al. (2017) e Salvi et al. (2017) em áreas sob a influência de elevados níveis de salinidade na Ásia, foi semelhante aos encontrados nas áreas experimentais no perímetro irrigado do município de Pentecoste-CE.

$\mathrm{Na}$ área de estudo, dentre os fatores ambientais que apresentam intrínseca relação com a estrutura do componente herbáceo está a sazonalidade climática (pluviosidade), que exerce forte influência sobre a composição de espécies, uma vez que este estrato se torna ausente por um período prolongado do ano (período seco), aparecendo com maior frequência na estação chuvosa (Oliveira, 2013).

Türkmen e Kazanci (2010) indicam que valores do índice de Shannon menores que 1,0 aponta para um ambiente sob algum tipo de poluição ou degradação no habitat, o que pode ser explicado pelo estresse salino presente nas áreas.

As maiores diversidades, assim como a maior semelhança indicada pelo índice de Sorensen e pela análise Cluster por UPGMA entre as coletas realizadas no período das chuvas pode ser explicada pelo fator de que as sementes, inclusive das plantas classificadas como halófitas e halotolerantes, procuram condições mais amenas para germinarem, aumentando assim a sua sobrevivência, desta forma, um ambiente mais húmido devido às chuvas se torna mais propício à germinação das sementes presentes no banco de sementes do solo (Costa e Herrera, 2016a).

\section{Conclusões}

Em função dos resultados obtidos no Perímetro Irrigado em Pentecoste-CE, conclui-se que:

1. Foi possível identificar gradientes de salinidade no solo em função das CEes variando 
entre 0,31 e $17,5 \mathrm{dS} \mathrm{m}^{-1}$, sendo as maiores encontradas na época seca;

2. Foram amostrados 6.573 indivíduos, divididos em 14 famílias e 37 espécies. A família com maior diversidade de espécies foi a família Fabaceae com 8 espécies, seguido das famílias Malvaceae e Poaceae, com 6 e 5 espécies, respectivamente;

3. Foi possível identificar nas áreas pesquisadas espécies de halófitas como Sesuvium portulacastrum, Blutaparon vermiculare e Ipomoea pes-caprae, assim como espécies cuja tolerância ao estresse salino ainda foi pouco explorado, como Cyperus rotundus, Malachra fasciata, Desmanthus virgatus e Eragrostis plana, sugerindo assim uma investigação acerca desta tolerância;

4. As espécies da família Apocynaceae Calotropis procera e Cryptostegia madagascariensis são espécies invasoras exóticas presentes na área de estudo que manifestam leve tolerância à salinidade do solo, que sabidamente podem modificar a estrutura das comunidades invadidas, ocasionando perda de biodiversidade;

5. A maior riqueza de espécies (S) obteve-se no pico da estação chuvosa, com 24 espécies;

6. A análise de Cluster por UPGMA corrobora a maior similaridade encontrada entre as coletas realizadas na quadra chuvosa na área 1 e as coletas realizadas na quadra chuvosa na área 2;

7. Observa-se também o amplo potencial das espécies listadas, como por exemplo, com fins medicinais, alimentícios, para aproveitamento em programas de haloforraginocultura e na recuperação de solos degradados.

\section{Agradecimentos}

À Fundação Cearense de Apoio ao Desenvolvimento Científico e Tecnológico (FUNCAP), pela concessão da bolsa de Mestrado do Fundo de Incentivo à Inovação Tecnológica (FIT) ao segundo autor. Ao Programa de Pós-graduação em Engenharia Agrícola da Universidade Federal do Ceará, pelo apoio na execução da pesquisa. À Universidade Estadual do Ceará, pela disponibilização do transporte para deslocamento ao local da pesquisa.

\section{Referências}

Albuquerque, A.G.B.M., Ferreira, T.O., Cabral, R.L., Nóbrega, G.M., Romero, R.E., Meireles, A.J.D.A., Otero, X.L., 2014. Hypersaline tidal flats (apicum ecosystems): the weak link in the tropical wetlands chain. Environmental Reviews 22, 99-109.

Albuquerque, J.A., Costa, R.N.T., Ribeiro, R.S.F., Gheyi, H.R., 2018. Responsabilidade objetiva na geração de passivo ambiental pela irrigação. IRRIGA 23, 402-412.

Albuquerque, U.P., Muniz, D.M.P., Almeida, A.L., Monteiro, J.M., Machado, D.F.L.N., Gomes, D.M.J., Santos, J.P., 2007. Medicinal plants of Caatinga (semi-arid) vegetation of NE Brazil: a qualitative approach. Journal of Ethnopharmacology 114, 325-354.

Almeida Júnior, L.D., Quaglio, A.E.V, Costa, C.A.R.A., Di Stasi, C., 2017. Intestinal antiinflammatory activity of ground cherry (Physalis angulata L.) standardized $\mathrm{CO}_{2}$ phytopharmaceutical preparation. World Journal of Gastroenterology 23, 4369-4380.

Andrade, L.A., 2013. Plantas invasoras: espécies exóticas invasoras da Caatinga e ecossistemas associados. 1. ed. Campina Grande, Epgraf.

Araújo, E.L., Silva, K.A., Ferraz, E.M.N., Sampaio, E.V.S.B., Silva, S.I., 2005. Diversidade de herbáceas em microhábitats rochoso, plano e ciliar em uma área de Caatinga, Caruaru-PE, Brasil. Acta Botânica Brasílica 19, 285-294.

Bezerra, E., 2006. A salinização de solos aluviais em perímetros irrigados no Estado do Ceará. Fortaleza, DNOCS.

Brower, J.E., Zar, J.H., 1984. Field and Laboratory Methods for General Ecology. 2 nd edition. Iowa, Wm. C. Brown Publishers.

Cantero, J.J., Palchetti, V., Núñez, C.O., Barbosa, G.E., 2016. Halophytic flora of Argentina: a checklist and na analysis of its diversity. In: Khan, M.A., Boër, B., Ozturk, M., Clusëner-Godt, M., Gul, B., Breckle, S.W. (Eds.). Sabkha ecosystems V: the Americas. Berlin, Springer.

Corrêa, M.P., 1984. Dicionário de plantas úteis do Brasil e das exóticas cultivadas. Rio de Janeiro, Imprensa Nacional.

Costa, C.S.B, Iribarne, O.O., Farina, J.M., 2009. Human impacts and threats to the conservation of South American salt marshes. In: Silliman, B.R., Grosholtz, T., Bertness, M.D. (Ed.) Salt marshes under global siege. Berkeley, University of California Press. 
Costa, C.S.B., 2011. Restoration of coastal salt marshes in Brazil using native salt marsh plants. In: Greipsson, S. (Ed.). Restoration ecology. Sudbury, Jones \& Barlett Learning.

Costa, C.S.B., Herrera, O.B., 2016a. Halophytic life in brazilian salt flats: biodiversity, uses and threats. In: Khan, M.A., Boër, B., Ozturk, M., Clusëner-Godt, M., Gul, B., Breckle, S.-W. (Eds.) Sabkha ecosystems V: the Americas. Berlin, Springer.

Costa, C.S.B., Herrera, O.B., 2016b. Halófitas brasileiras: Formas de cultivo e usos. In: Gheyi, H.R., Dias, N.D., Lacerda, C.F., Gomes-Filho, E. (ed.) Manejo da salinidade na agricultura: estudos básicos e aplicados. Fortaleza, INCTSal.

Costa, K.C., Lima, A.L.A., Fernandes, C.H.M., Silva, M.C.N.A., Silva, A.C.B.L., Rodal, M.J.N., 2009. Flora vascular e formas de vida em um hectare de Caatinga no Nordeste brasileiro. Revista Brasileira de Ciências Agrárias 4, 48- 54.

Couto, R.S., Cardoso, L.J.T., 2017. Aizoaceae in Flora do Brasil 2020 em construção. Rio de Janeiro, Jardim Botânico do Rio de Janeiro. Disponível em: <http://floradobrasil.jbrj.gov.br/reflora/florad obrasil/FB4256>. Acesso em: 9 set. 2017.

Cunha, J.L.X.L., Freitas, F.C.L., Coelho, M.E.H., Silva, M.G.O., Silva, K.S., Nascimento, P.G.M.L., 2014. Fitossociologia de plantas daninhas na cultura do pimentão nos sistemas de plantio direto e convencional. Revista Agro@mbiente On-line 8, 119-126. Disponível em: $<$ http://digitalcommons.usu.edu/cgi/viewcont ent.cgiarticle $=1042 \&$ context $=$ extension_hista 1l>. Acesso em: 7 de jun. 2017.

DNOCS., 1976. Projeto Curu-Recuperação: Sistema General Sampaio - Missão de Israel. 2.DR/Ceará. Anexo I, R-798/76.

DNOCS., 2017. Perímetros Irrigados DNOCS. Disponível em: <http://www.dnocs.gov.br/ dnocs/doc/canais /perimetros_irrigados/ce/curu_pentecoste.htm 1>. Acesso em: 9 jul. 2017.

EMBRAPA., 2001. Centro Nacional de Pesquisa de Agroindústria Tropical. Dados Climatológicos: Estação de Pentecoste. Fortaleza, Embrapa Agroindústria Tropical.

EMBRAPA., 2011. Manual de Métodos de Análise de Solo. 2. ed. Rio de Janeiro, EMBRAPA.

EMBRAPA., 2013. Sistema brasileiro de classificação de solos. 3. ed. Rio de Janeiro, Embrapa solos.
Fernandes-Júnior, A.J., 2017. Malachra in Flora do Brasil 2020 em construção. Rio de Janeiro, Jardim Botânico do Rio de Janeiro. Disponível em: <http://floradobrasil.jbrj.gov.br/reflora/florad obrasil/FB19535>. Acesso em: 9 set. 2017.

Fidalgo, O., Bononi, V.L.R., 1989. Técnicas de coleta, preservação e herborização de material botânico. São Paulo, Instituto de Botânica.

Flores-Olvera, H., Czaja, A., Estrada-Rodríguez, J.L., Méndez, U.R., 2016. Floristic diversity of halophytic plants of Mexico. In: Khan, M.A., Boër, B., Ozturk, M., Clusëner-Godt, M., Gul, B., Breckle, S.-W. (Eds.). Sabkha ecosystems V: the Americas. Berlin, Springer.

Flowers, T.F., Galal, H.K., Bromham, L., 2010. Evolution of halophytes multiple origins of salt tolerance in land plants. Functional Plant Biology 37, 604-612.

Frosi, G., Oliveira, M.T., Almeida-Cortez, J., Santos, M.G., 2013. Ecophysiological performance of Calotropis procera: an exotic and evergreen species in Caatinga, Brazilian semi-arid. Acta Phisiologiae Plantarum 35, 335-344.

García, M., Jáuregui, D., Medina, E., 2008. Adaptaciones anatómicas foliares en especies de angiospermas que crecen en la zona costera del estado Falcón (Venezuela). Acta Botánica Venezuela 31, 291-306.

Grabarczyk, M., Winska, K., Maczka, W., Potaniec, B., Aniol, M., 2015. Loliolide - the most ubiquitous lactone. Folia Biologica et Oecologica 11, 1-8.

Instituto Brasileiro de Geografia e Estatística., 2012. Manual técnico da vegetação brasileira. 2. ed. Rio de Janeiro, IBGE.

IPECE., 2017. Instituto de Pesquisa e Estratégia Econômica do Estado do Ceará. Disponível em:

<http://www.ipece.ce.gov.br/perfil_basico_m unicipal/2016/Pentecoste.pdf $>$. Acesso em: 9 jul. 2017.

Kotuby-Amacher, J., Koening, R., Kitchen, B., 2000. Salinity in plant tolerance. Logan, Utah state University electronic publishing.

Leão, T.C.C., Almeida, W.R., Dechoum, M., Ziller, S.R., 2011. Espécies exóticas invasoras no Nordeste do Brasil: contextualização, manejo e políticas públicas. Recife, Centro de Pesquisas Ambientais do Nordeste e Instituto Hórus de Desenvolvimento e Conservação Ambiental.

Lee, I., Lee, J., Kim, D.S., Park, K.W., 2014. Current status and perspective of weed 
science in Asian Pacific Region. Weed \& Turfgrass Science 3, 1-5.

Lokhande, V.H., Nikam, T.D., Suprasanna, P., 2009. Sesuvium portulacastrum L. a promising halophyte: cultivation, utilization and distribution in India. Genetic Resource and Crop Evolution 56, 741-747.

Lucena, E.M.P., Herrera, O.B., Major, I., 2015. Frutas da Caatinga cearense. 1. ed. Fortaleza, EdUECE.

Major, I., Sales, J.C., 2010. Solo e poluição. In: Lucena, E.M.P. (Org.). Mudanças climáticas e desenvolvimento sustentável. 1. ed. Fortaleza: Universidade Aberta do Nordeste.

Medeiros, J.F., Gheyi, H.R., Costa, A.R.F.C., Tomaz, H.V.Q., 2016. Manejo do solo-águaplanta em áreas afetadas por sais. In: Gheyi, H.R., Dias, N.S., Lacerda, C.F., Gomes Filho, E. (Eds.). 2. ed. Manejo da salinidade na agricultura: estudos básicos e aplicados. Fortaleza, INCTSal.

Medeiros, J.F., Gheyi, H.R., Nascimento, L.B., 2012. Salinidade de solo e da água e seus efeitos na produção agrícola. In: Gheyi, H.R., Paz, V.P.S., Medeiros, S.S., Galvão, C.O., Recursos hídricos em regiões semiáridas: estudos e aplicações. Campina Grande, INSA.

Medeiros, M.F.T., Albuquerque, U.P., 2014. Food flora in 17th century northeast region of Brazil in historia naturalis brasiliae. Journal of Ethnobiology and Ethnomedicine 10, 1050.

Medina, E., 2016. Physiological ecology of psammophytic and halophytic plant species from coastal plains in Northern South America. In: Khan, M.A., Boër, B., Özturk, M., Clüsener-Godt, M., Gul, B., Breckle, S.W. (Eds.). Sabkha ecossistems V: the Americas. Berlin, Springer.

Medina, E., Francisco, A.M., Wingfield, R., Casañas, O.L., 2008. Halofitismo en plantas de la costa caribe de Venezuela: Halófitas y halotolerantes. Acta Botánica Venezuela 31, 49-80.

Meira de Andrade, M.V., 2009. Levantamento florístico e estrutura fitossociológica do estrato herbáceo e subarbustivo em áreas de Caatinga no Cariri paraibano. Revista Caatinga 22, 229-237.

Mętrak, M., Chachulski, L., Navruzshoev, D., Pawlikowsvi, P., Rojan, E., Sulwinski, M., Sulska-Malawska, M., 2017. Nature's patchwork: how water sources and soil salinity determine the distribution and structure of halophytic plant communities in arid environments of the Eastern Pamir. Plos One 12, 1-23.

Mishra, N.K., Sangwan, A., 2016. Phytoremediation of salt-affected soils: a review of processes, applicability and impact on soils health in Hisar Haryana. International Journal of Engineering Science Invention Research and Development 2, 418423.

Moro, M.F., Macedo, M.B., Moura-Fé, M.M., Castro, A.S.F., Costa, R.C., 2015. Vegetação, unidades fitoecológicas e diversidade paisagística do estado do Ceará. Rodriguésia 66, 717-743.

Mukhopadhyay, S., Rana, V., Kumar, A., Maiti, S.K., 2017. Biodiversity variability and metal accumulation strategies in plants spontaneously inhibiting fly ash lagoon, India. Environmental Science and Pollution Research, 1-16.

Nnamani, C.V., Ani, O.C., Belunwu, G., 2009. Larvicidal effects of etanol extracts of leaves and fruits of Physalis angulata L. on the larvae of Anopheles mosquitoes from Ebonyi state, Nigeria. Animal Research International 6, 1059-1062.

Oliveira, A.N., Amaral, I.L., 2004. Florística e fitossociologia de uma floresta de vertente na Amazônia Central, Amazonas, Brasil. Acta Amazônica 34, 21-34.

Oliveira, D.G., Prata, A.P., Ferreira, R.A., 2013. Herbaceas da Caatinga: composição florística, fitossociologia e estratégias de sobrevivência em uma comunidade vegetal. Revista Brasileira de Ciências Agrárias 8, 623-633.

Pandolfi, C., Mancusoa, S., Shabalab, S., 2012. Physiology of acclimation to salinity stress in pea (Pisum sativum). Environmental and Experimental Botany 84, 44-51.

Paz, V.P.S., Medeiros, S.S., Galvão, C.O., 2012. Recursos hídricos em regiões semiáridas: estudos e aplicações. Campina Grande, INSA.

Pizarro, F.C., 1976. Drenaje agrícola y recuperación de suelos salinos. Fortaleza, MINTER/SUDENE/DNOCS.

Queiroz, G.R., Ribeiro, R.C.L., Romão, F.T.N. M.A., Flaiban, K.K.M.C., Bracarense, A.P.F.R.L., Lisboa, J.A.N., 2012. Intoxicação espontânea de bovinos por Senna obtusifolia no Estado do Paraná. Pesquisas veterinárias brasileiras 32, 1263-1271.

Rao, B.R.P., Sridhar, R.R.M, Pullaiah, T., 2008. Flora and vegetation of Andhra Phradesh. New Delhi Akademy of Sciences 12, 1-13. 
Ribeiro, M.R., 2010. Origem e classificação dos solos afetados por sais. In: Gheyi, H.R., Dias, N.S., Lacerda, C.F. (Eds.). Manejo da salinidade na agricultura: estudos básicos e aplicados. Fortaleza, INCTSal.

Richards, L.A., 1974. Suelos salinos y sódicos: diagnóstico y rehabilitacion. 6. ed. México, Editorial Limusa.

Rodrigues, A.P.M.S., Mendonça, A.F.J., Costa, E.M., Araújo, J.A.M., Paula, V.F.S., 2016. Levantamento fitossociológico de plantas daninhas na cultura da cenoura em monocultivo e consorciada com rabanete. Revista Verde de Agroecologia e Desenvolvimento Sustentável 11, 73-77.

Rodrigues, M.H.B.S., Pereira, E.B.J., Andrade, F.E., Nascimento, D.M., Vale, K.S., Hafle, O.M., 2017. Fitossociologia de plantas espontâneas sob cultivo agroecológico na bananeira no Sertão Paraibano. Revista Verde de Agroecologia e Desenvolvimento Sustentável 12, 12-16.

Rozema, J., Schat, H., 2013. Salt tolerance of halophytes, research questions reviewed in the perspective of saline agriculture. Environment and Experimental Botany 2, 8395.

Ruiz, K.B., Biondi, S., Martínez, E.A., Orsini, F., Antognoni, F., Jacobsen, S.E., 2015. Quinoa - a model crop for understandig salttolerance mechanisms in halophytes. Plant Biosystems 149, 357-371.

Salvi, H., Das, L., Brahmbhatt, B., Vaghela, N., Kamboj, R.D., 2017. Diversity of halophytes in Gulf oh Kachchh, Gujarat. International Journal of Life Sciences Scientific Research, India 3, 995-1002.

Senna, L., Marchioretto, M.S., 2015. Blutaparon in Lista de Espécies da Flora do Brasil. Rio de Janeiro, Jardim Botânico do Rio de Janeiro. Disponível em: <http://floradobrasil.jbrj.gov.br/jabot/florado brasil/FB15412>. Acesso em: 30 dez. 2015.

Shepherd, G.J., 2010. FITOPAC-Versão 2.1. Campinas, UNICAMP.

Silva, K.A., Araújo, E.L., Ferraz, E.M.N., 2009. Estudo florístico do componente herbáceo e relação com solos em áreas de Caatinga do embasamento cristalino e bacia sedimentar, Petrolândia-PE, Brasil. Acta Botânica Brasílica 23, 100-110.

Sousa, F.Q., Andrade, L.A., Xavier, K.R.F., 2016. Cryptostegia madagascariensis Bojer ex Decne.: impactos sobre a regeneração natural em fragmentos de Caatinga. Revista Brasileira de Ciências Agrárias 11,39-45.
Sousa, R.S., 2010. Etnobotânica e etnozoologia de comunidades pesqueiras da Área de Proteção Ambiental (APA) do Delta do Parnaíba, Nordeste do Brasil. Dissertação (Mestrado). Teresina, Universidade Federal do Piauí.

Souza, N.K.R., Alcântara Júnior, J.P., Amorim, S.M.C., 2007. Efeito do estresse salino sobre a produção de fitomassa em Physalis angulata $\mathrm{L}$. (Solanaceae). Revista Acadêmica 5, 379-384.

Souza, T.A.F., Andrade, L.A., Freitas, H., Sandim, A.S., 2017. Biological invasion influences the outcome of plant-soil feedback in the invasive plant species from the brazilian semi-arid. Microbial Ecology, 1-11.

Souza, T.A.F., Rodriguez-Echeverría, S., Andrade, L.A., Freitas, H., 2016. Could biological invasion by Cryptostegia madagascariensis alter the composition of the arbuscular mycorrhizal fungal community in semi-arid Brazil. Acta Botânica Brasilica 30, 93-101.

Tavares Filho, A.N.T., Barros, M.F.C., Rolim, M.M., Silva, E.F.F., 2012. Incorporação de gesso para correção da salinidade e sodicidade de solos salino-sódicos. Revista Brasileira de Engenharia Agrícola e Ambiental 16, 247-252.

Torres, C.R.M., Fernando, E.M.P., Lucena, M.F.A., 2016. Checklist de plantas aquáticas em trechos de Caatinga do semiárido paraibano, Nordeste do Brasil. Gaia Scientia 10, 284-296.

Turkmen, G., Kazanci, N., 2010. Applications of various biodiversity indices to benthic macro invertebrate assemblages in streams of a national park in Turkey. Review of Hydrobiology, Research article 3, 111-125.

USSL STAFF., 1954. United States Salinity Laboratory Staff: diagnosis and improvement of saline and alakali soils. Washington, U.S. Department of Agriculture.

Yang, Y.-C., Lim, M.-Y., Lee, H.-S., 2003. Emodin isolated from Cassia obtusifolia (Leguminosae) seed shows larvicidal activity against three mosquito species. Journal of Agricultural and Food Chemistry 51, 76297631.

Zerai, D.B., Glenn, E.P., Chaterverdi, R.L.U.Z., Mamood, A.N., Nelson, S.G., Ray, D.T., 2010. Potential for the improvement of $S$. bigelovii thought selective breeding. Ecological Engineering 36, 730-739. 